\title{
Modifying bacterial flagellin to evade Nod-like Receptor CARD 4 recognition enhances protective immunity against Salmonella
}

\author{
Panagiotis Tourlomousis $\mathbb{1}^{1}$, John A. Wright ${ }^{1,4}$, Alessandra S. Bittante ${ }^{1,4}$, Lee J. Hopkins ${ }^{1}$, \\ Steven J. Webster', Owain J. Bryant ${ }^{2}$, Pietro Mastroeni', Duncan J. Maskell ${ }^{1}{ }^{1,3}$ and \\ Clare E. Bryant $\mathbb{B}^{1 凶}$
}

Pattern recognition receptors (PRRs) expressed in antigen-presenting cells are thought to shape pathogen-specific immunity by inducing secretion of costimulatory cytokines during T-cell activation, yet data to support this notion in vivo are scarce. Here, we show that the cytosolic PRR Nod-like Receptor CARD 4 (NLRC4) suppresses, rather than facilitates, effector and memory CD4 ${ }^{+}$T-cell responses against Salmonella in mice. NLRC4 negatively regulates immunological memory by preventing delayed activation of the cytosolic PRR NLR pyrin domain 3 (NLRP3) that would otherwise amplify the production of cytokines important for the generation of Th1 immunity such as intereukin-18. Consistent with a role for NLRC4 in memory immunity, primary challenge with Salmonella expressing flagellin modified to largely evade NLRC4 recognition notably increases protection against lethal rechallenge. This finding suggests flagellin modification to reduce NLRC4 activation enhances protective immunity, which could have important implications for vaccine development against flagellated microbial pathogens.

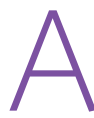
ntigen-presenting cells (APCs) recognize pathogens via pattern recognition receptors (PRRs), such as the transmembrane Toll-like receptors (TLRs) and the cytosolic nucleotide oligomerization domain (NOD)-like receptors (NLRs) ${ }^{1,2}$. PRR activation induces APCs to secrete proinflammatory cytokines during presentation of antigens to naive $\mathrm{T}$ cells leading to their differentiation into the most appropriate subset of activated $\mathrm{T}$ cells to eliminate the pathogen ${ }^{3}$. The bridge between the innate and adaptive immune systems is, therefore, formed by PRR activation in APCs. Central to this is the concept that the repertoire of PRRs expressed by APCs is crucial to the specificity of adaptive immune response generated ${ }^{4}$. The increasing prevalence of antimicrobial resistance means the development of alternative ways to combat infectious diseases is a matter of urgency. Understanding the interactions between pathogens, PRRs and pathogen-specific immunity is, therefore, important to facilitate the development of new vaccines with improved efficacy.

Microbial pathogens produce a number of pathogen-associated molecular patterns that are recognized by different PRRs. Lipopolysaccharide (LPS) from Gram-negative bacteria, for example, is recognized by TLR4 and flagellin by TLR5. Both flagellin and detoxified LPS molecules are used as vaccine adjuvants with flagellin being an antigenic target of antibody and $\mathrm{CD}^{+}{ }^{+} \mathrm{T}$-cell responses $^{5}$. The NOD-like receptor CARD 4 (NLRC4) also recognizes microbial flagellin ${ }^{6,7}$, but, in addition, senses the type III secretion system-associated needle and rod proteins ${ }^{8}$ via the NLR family, apoptosis inhibitory protein (NAIP) 5 or NAIP6 and NAIP1 or NAIP2 in mice ${ }^{9-11}$. NLR pyrin domain 3 (NLRP3) is activated by a diverse range of triggers, including pathogen-associated molecular patterns and danger-associated molecular patterns. NLR activation drives the formation of an inflammasome signalling complex ${ }^{12}$, which activates caspase- 1 to process pro-IL- $1 \beta$ and pro-IL-18 to their mature forms and cleaves gasdermin D to drive an inflammatory form of cell death called pyroptosis ${ }^{13,14}$. NLRC4 and NLRP3 can be recruited to the same inflammasome to optimize IL- $1 \beta$ and IL-18 release $\mathrm{r}^{15,16}$.

IL-1 $\beta$ and IL-18 have well-documented effects on T-cell survival, activation and differentiation ${ }^{17}$. Little is known, however, about whether and how specific inflammasome components influence the development of adaptive immunity against pathogenic bacteria and, specifically, that of immunological memory, which is critical for vaccine development ${ }^{4}$. It has been shown, for example, that NLRC4 and NLRP3 activation in innate immune cells optimizes interferon- $\gamma\left(\right.$ IFN- $\gamma$ ) release by $\mathrm{CD}^{+}$and $\mathrm{CD}^{+} \mathrm{T}$ cells in mice challenged with Salmonella enterica serovar Typhimurium (S. Typhimurium), but this was not an antigen-specific effect ${ }^{18,19}$. Here, using the murine model of sublethal salmonellosis, we show that NLRC4 suppresses Th1 CD4 ${ }^{+}$T-cell effector and memory responses against $S$. Typhimurium without affecting antibody production. Primary challenge with $S$. Typhimurium engineered to reduce NLRC4 inflammasome activation resulted in increased levels of serum IL-18 and IFN- $\gamma$, enhanced Th1 CD4 $4^{+}$T-cell memory responses and improved protection against oral rechallenge with fully virulent Salmonella. Our data indicate that attenuation of NLRC4 activation by flagellin could improve the efficacy of live vaccines against flagellated pathogens such as Salmonella, and potentially that of flagellin-based adjuvants.

\section{Results}

NLRC4 restricts bacterial load in vivo and Th1 memory responses ex vivo. To investigate whether NLRC4 affects the development of pathogen-specific immunity, we first challenged C57BL/6J

'Department of Veterinary Medicine, University of Cambridge, Cambridge, UK. ${ }^{2}$ Department of Pathology, University of Cambridge, Cambridge, UK. ${ }^{3}$ Present address: The University of Melbourne, Parkville, Victoria, Australia. ${ }^{4}$ These authors contributed equally: John A. Wright, Alessandra S. Bittante. 凶e-mail: ceb27@cam.ac.uk 

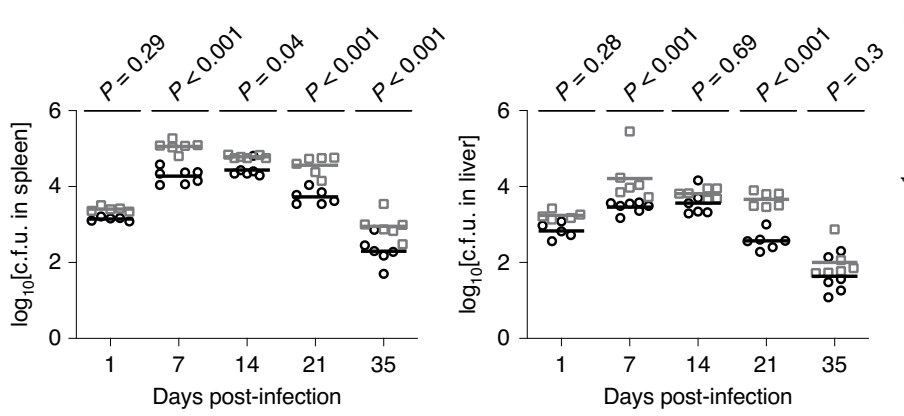

Wild type $(n=12)$
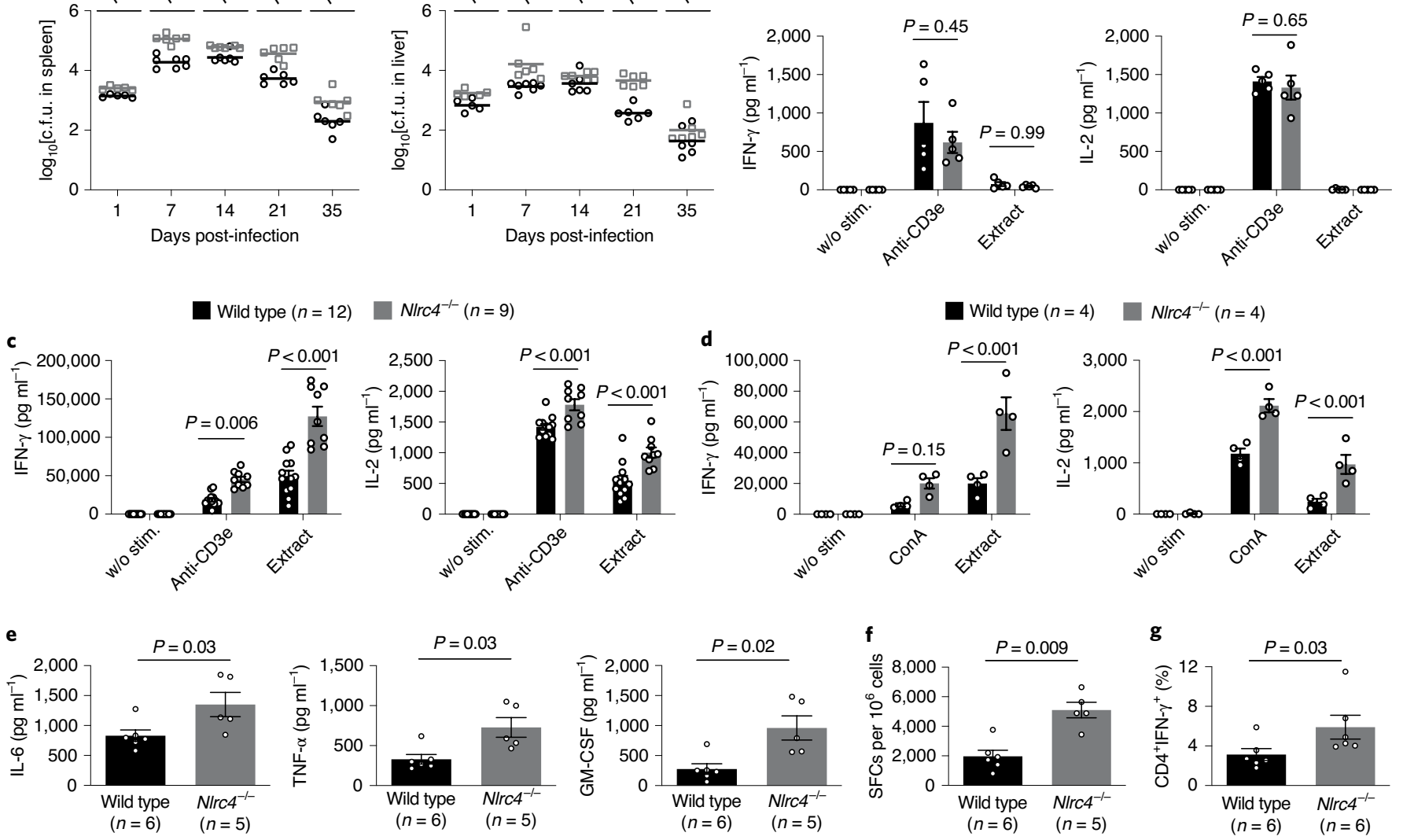

Fig. 1 | NLRC4 restricts bacterial spread in vivo and Th1 CD4+ T-cell-mediated memory responses ex vivo. a, Wild-type and N/rc4-/- mice were challenged i.v. with $9.5 \times 10^{3}$ c.f.u. S. Typhimurium M525P and microbial burden was determined in the spleen and liver at day 1 ( $n=5$ for wild-type and Nlrc4 $\left.{ }^{-/-}\right), 7$ ( $n=7$ for wild-type and $n=6$ for N/rc4 ${ }^{-/}$), 14, 21 and 35 ( $n=6$ for wild-type and N/rc4 ${ }^{-/-}$) post-challenge. b, CD4+ T cells from naïve wild-type and N/rc4 $4^{-1-}$ mice were stimulated ex vivo with medium only (without (w/o) stim.), antimouse CD3e (anti-CD3e) or whole bacterial cell extract (extract). Levels of IFN- $\gamma$ and IL-2 were measured by ELISA in the cell culture supernatant after 72 and 24 h, respectively. c, CD4 ${ }^{+}$T cells from wild-type and N/rc4 ${ }^{-/-}$ mice $90 \mathrm{~d}$ after challenge with $7 \times 10^{3}-1 \times 10^{4}$ c.f.u. of S. Typhimurium M525P were stimulated and levels of IFN- $\gamma$ and IL-2 were measured as in b. $\mathbf{d}$, CD4+ T cells from wild-type and N/rc4 ${ }^{-/-}$mice $168 \mathrm{~d}$ after challenge with $1.15 \times 10^{3}$ c.f.u. of S. Typhimurium M525P were stimulated as in $\mathbf{b}$, with the exception that concanavalin A (conA) was used instead of antimouse CD3e, and levels of IFN- $\gamma$ and IL-2 were measured as in $\mathbf{b}$. e, CD4+ $\mathrm{T}$ cells from wild-type and N/rc4 $4^{-1-}$ mice $90 \mathrm{~d}$ after challenge with $7 \times 10^{3}$ c.f.u. of S. Typhimurium M525P were stimulated with whole bacterial cell extract and levels of IL-6, TNF- $\alpha$ and GM-CSF were measured by fluorescent bead immunoassay in the cell culture supernatant after $24 \mathrm{~h}$. $\mathbf{f}$, Same experiment as e, the number of CD4+

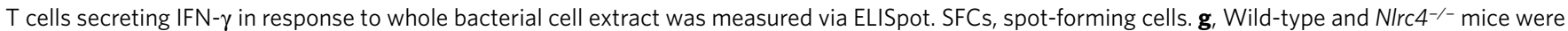
challenged i.v. with $1.72 \times 10^{4}$ c.f.u. and $112 \mathrm{~d}$ later, the percentage of CD4+ $\mathrm{T}$ cells secreting IFN- $\gamma$ in response to whole bacterial cell extract was measured via a cytokine secretion assay. Each symbol represents one mouse with horizontal lines delineating the mean in $\mathbf{a}$. Data are shown as mean $\pm \mathrm{s}$.e.m. in $\mathbf{b}$ - $\mathbf{g}$. Data are pooled from two and representative of at least four independent experiments for $\mathbf{c}$ and representative of three for $\mathbf{a}$ and two for $\mathbf{b}$, $\mathbf{d}$-g independent experiments. Statistical significance was calculated by a two-way ANOVA followed by Sidak's multiple comparisons tests for a-d and two-tailed Mann-Whitney test for $\mathbf{e}-\mathbf{g}$.

wild-type and congenic Nlrc4 ${ }^{-/-}$mice with $S$. Typhimurium M525P. In this model of sublethal salmonellosis, effector Th1 $\mathrm{CD}^{+} \mathrm{T}$ cells drive microbial clearance and establish long-term protection against rechallenge ${ }^{20,21}$. $\mathrm{NlrC4}^{-/-}$mice harboured higher microbial numbers in the liver and spleen irrespective of the route of bacterial administration (intravenous (i.v.) in Fig. 1a or oral in Extended Data Fig. 1a). Bacterial burden, as expected ${ }^{22,23}$, was not significantly different between $\mathrm{NlrC4}^{-/-}$and wild-type mice lethally challenged with fully virulent S. Typhimurium SL1344 (Extended Data Fig. 1b). The slower kinetics of the sublethal infection reveal a clear role for NLRC4 in regulating bacterial load in vivo.

We determined whether NLRC4 would play any role in the development of memory CD4 ${ }^{+}$T-cell responses. Wild-type and $\mathrm{NlrC4}^{-/-}$ mice were challenged with PBS (naïve) or $10^{4}$ colony-forming units (c.f.u.) of S. Typhimurium M525P, an inoculum size that was equally immunogenic to a tenfold higher dose in wild-type mice (Extended Data Fig. 2) and well tolerated by the $\mathrm{Nlrc} 4^{-/-}$mice. To elicit a response from memory cells only, $\mathrm{CD} 4^{+} \mathrm{T}$ cells were isolated from mice that had cleared the primary infection after a minimum of $90 \mathrm{~d}$. On stimulation with bacterial extract (antigen-specific), $\mathrm{CD} 4^{+} \mathrm{T}$ cells from naïve mice, irrespective of genotype, secreted negligible amounts of the Th1 cytokines IFN- $\gamma$ and IL-2 (Fig. 1b), confirming the specificity of the response generated by $\mathrm{CD}^{+} \mathrm{T}$ cells from infected mice (Fig. 1c). Similarly, the amount of IFN- $\gamma$ secreted by $\mathrm{CD} 4^{+} \mathrm{T}$ cells when stimulated with antimouse $\mathrm{CD} 3 \mathrm{e}$ (non-antigen-specific) increased more than 50-fold in response to infection (Fig. 1c). 
We compared the magnitude of the ex vivo memory responses between wild-type and $\mathrm{Nlrc} 4^{-/-}$mice. T cells from $\mathrm{Nlrc}^{-/-}$mice secreted more IFN- $\gamma$ and IL- 2 than cells from wild-type mice in response to both Salmonella antigen and antimouse CD3e (Fig. 1c). This amplified response persisted up to $170 \mathrm{~d}$ after challenge (Fig. 1d, concanavalin A was used in early experiments as a polyclonal stimulus but later replaced by antimouse $\mathrm{CD} 3 \mathrm{e})$. The Th1-related cytokines TNF- $\alpha$, IL- 6 and GM-CSF in the CD4+ T-cell culture supernatant from Nlrc4 $4^{-/-}$mice were also elevated (Fig. 1e). These data indicate that NLRC4 activation by Salmonella specifically restricts $\mathrm{CD} 4^{+} \mathrm{T}$-cell-mediated memory immunity.

We then quantified the number of $\mathrm{CD}^{+} \mathrm{T}$ cells secreting IFN- $\gamma$ in response to bacterial extract using ELISpot and cytokine secretion assays. Both assays showed a larger population of IFN- $\gamma$-secreting cells in $\mathrm{NlrC}^{-/-}$mice (Fig. 1f,g). We also analysed the surface expression of CD62L and CD44 in IFN- $\gamma^{+}$cells and found that over $90 \%$ in both wild-type and $\mathrm{NlrC}^{-/-}$mice had an effector memory $\mathrm{T}$-cell profile $\left(\mathrm{CD} 44^{\text {high }} \mathrm{CD} 62 \mathrm{~L}^{-}\right)$with central memory cells $\left(\mathrm{CD} 44^{\text {high }} \mathrm{CD} 62 \mathrm{~L}^{+}\right)$representing less than $5 \%$ of the population (Extended Data Fig. 3). These data indicate that NLRC4 restricts T-cell memory immunity against Salmonella by reducing the size of antigen-specific memory pool.

To test whether NLRC4 could also affect protection against lethal rechallenge in vivo, wild-type and $\mathrm{NlrC4}^{-/-}$mice were systemically challenged with $S$. Typhimurium M525P and, after clearing the primary infection, rechallenged orally with fully virulent Salmonella. $\mathrm{Nlrc}^{-/-}$mice were only marginally better protected than their wild-type counterparts (Extended Data Fig. 4b, mean survival time of 9 versus $8 \mathrm{~d}$, respectively), an outcome that may have been affected by the different routes of infection between primary challenge (i.v.) and rechallenge (orally). In the same trial, however, naïve $\mathrm{Nlrc}^{-/-}$mice lethally challenged with Salmonella had shorter survival times than naïve wild-type mice (Extended Data Fig. $4 \mathrm{a}$, 6 versus $8 \mathrm{~d}$, respectively). These data indicate that, in the absence of NLRC4, the compromised innate immune control of microbial dissemination presumably counteracts any benefits arising from augmented T-cell memory immunity.

NLRC4 restricts Th1 effector responses during microbial clearance of a primary infection. To determine whether NLRC4 also affects the development of Th1 effector immunity, we isolated splenic $\mathrm{CD}^{+} \mathrm{T}$ cells from infected wild-type and $\mathrm{NlrC4}^{-/-}$mice during an active primary infection and measured the amount of IFN- $\gamma$ released ex vivo. Production of IFN- $\gamma$ in response to bacterial extract was comparable between the two genotypes when $\mathrm{CD} 4^{+} \mathrm{T}$ cells were isolated early during infection (Figs. 2a, 1 and $7 \mathrm{~d}$ ). Notably, as the infection progressed into the phase of $\mathrm{CD} 4^{+} \mathrm{T}$-cell-mediated bacterial clearance, $\mathrm{T}$ cells from $\mathrm{Nlrc}^{-/-}$mice secreted significantly more IFN- $\gamma$ than cells from wild-type mice (Fig. $2 \mathrm{a}, 14$ and $21 \mathrm{~d}$ ). By the end of microbial clearance, however, there were no difference in Th1 responses between $\mathrm{Nlrc}^{-/-}$and wild-type mice (Fig. 2a, 35d). Salmonella-induced Th1 CD4 ${ }^{+}$T-cell responses can also affect the development of B-cell-dependent immunity ${ }^{24}$, so we measured the levels of serum antibodies against $S$. Typhimurium LPS at $90 \mathrm{~d}$ after primary infection. We found no difference in the levels of IgG2c, IgG2 $\mathrm{b}$ and IgM between wild-type and $\mathrm{NlrC}^{-/-}$mice (Fig. 2b). These data collectively show that NLRC4 restricts both Th1 CD4 ${ }^{+}$ T-cell-mediated effector and memory immune responses against Salmonella, but has no effect on B-cell-mediated immunity.

Negative regulation of $\mathrm{CD4}^{+} \mathrm{T}$-cell-mediated memory responses by NLRC4 is NLRP3-dependent. NLRC4 is not expressed in naïve or activated $\mathrm{CD}^{+} \mathrm{T}$ cells ${ }^{25,26}$. We proposed, therefore, that any effect on $\mathrm{CD}^{+}{ }^{+} \mathrm{T}$-cell memory immunity is most likely to occur in response to inflammasome signalling by APCs. NLRC4 and NLRP3 are both activated in murine macrophages infected with
Salmonella ${ }^{22}$. We, therefore, assessed ex vivo the memory T-cell responses in $\mathrm{Nlrp3}^{-/-}$and $\mathrm{Nlrp3} 3^{-/-} \mathrm{Nlrc4} 4^{-/}$mice. Secretion of both IFN- $\gamma$ and IL-2 was comparable between wild-type, $\mathrm{Nlrp}^{-/-}$or $N \operatorname{Np} 3^{-/-} N l_{r C} 4^{-/-}$mice (Fig. 3a,b) and, as expected, we saw no difference in the numbers of $\mathrm{CD}^{+} \mathrm{T}$ cells secreting IFN- $\gamma$ in response to bacterial extract (Fig. 3c,d). To confirm that our independent comparisons between wild-type and $\mathrm{NlrC4}^{-/-}$(Fig. 1c), wild-type and

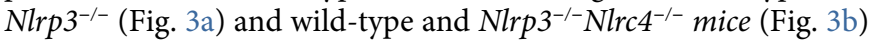
do not suffer from interexperimental variation, we compared IFN- $\gamma$ production between the different groups of wild-type mice used in these experiments and found no significant difference (Extended Data Fig. $5, P=0.25$ via one-way analysis of variance (ANOVA)). These data indicate that the amplification of memory $\mathrm{CD} 4^{+} \mathrm{T}$-cell responses seen the absence of $\mathrm{NlrC}^{-/-}$is driven by NLRP3 activation, while NLRP3 does not have an effect when NLRC4 is active.

NLRC4 restricts NLRP3-dependent production of IL-18 and IFN- $\gamma$. In macrophages infected with Salmonella SL1344, NLRC4 is activated rapidly to induce caspase-1-mediated pyroptosis and IL- $1 \beta$ and IL-18 release ${ }^{27}$, while NLRP3 activation is delayed to optimize IL-1 $\beta$ and IL-18 production without inducing pyroptosis ${ }^{15,22}$. Infection of wild-type and $\mathrm{Nlrp}^{-/-}$macrophages with S. Typhimurium M525P resulted in pyroptotic cell death within $2 \mathrm{~h}$ of infection, while $N \mathrm{NCH}^{-/-}$and $\mathrm{NlrC4} 4^{-/-} \mathrm{Nlrp3}^{-/-}$cells lysed between 6 and $12 \mathrm{~h}$ (Extended Data Fig. 6a). In the absence of NLRC4, cells produced IL- $1 \beta$ via NLRP3 and because these cells do not rapidly die, they secrete large amounts of IL- $1 \beta$ between 6 and $24 \mathrm{~h}$ (Extended Data Fig. $6 \mathrm{~b}$ ).

Both IL- $1 \beta$ and IL-18 are involved in initiation and propagation of antigen-specific immunity against bacterial pathogens, therefore, we examined whether NLRC4 and NLRP3 affect the production of these cytokines in vivo during infection with $S$. Typhimurium M525P. Serum IL-1 $\beta$ levels were below the detection limit, as expected ${ }^{22}$, throughout the course of infection. In Nlrc4 ${ }^{-/-}$mice, levels of IL-18 were lower $1 \mathrm{~d}$ after challenge, but as the sublethal infection progressed, they markedly increased when compared to those detected in wild-type mice (Fig. 4b). This increase coincided with the onset of effector $\mathrm{CD} 4^{+} \mathrm{T}$-cell-driven microbial clearance with IL-18 remaining elevated in $\mathrm{Nlrc}^{-/-}$mice for a total of 3 weeks (Fig. 4b, days 7 to 28). This corresponds to the time that $\mathrm{NlrC4}^{-/-}$mice have heightened effector $\mathrm{CD}^{+} \mathrm{T}$-cell responses (Fig. 2a) suggesting a link between the increased levels of IL-18 and increased Th1 immunity.

We tested whether this rise in serum IL-18 seen in $\mathrm{Nlrc4}^{-1-}$ mice was NLRP3-dependent. Nlrp $3^{-1-}$ and $N \operatorname{lrp} 3^{-/-} N \operatorname{lrc} 4^{-/-}$mice, such as $N$ lrc4 $4^{-/-}$mice, had decreased serum IL-18 levels very early during infection (Fig. 4b, day 1), but, unlike $\mathrm{NlrC}^{-/-}$mice, did not have increased IL-18 response as the infection progressed further (Fig. 4b, days 7-28). Nlrc $4^{-/-}$and $N \operatorname{lrp} 3^{-/-} \mathrm{Nlrc} 4^{-/-}$mice had similar bacterial burdens (Fig. 4a), but different IL-18 profiles (Fig. 4b), suggesting that this surge in serum IL-18 in the absence of NLRC4 depends on NLRP3 activation. IL-18 is a potent inducer of IFN- $\gamma^{28}$, which is indispensable for protection against Salmonella ${ }^{20,29}$. IFN- $\gamma$ levels in $\mathrm{Nlrc}^{-/-}$mice remained elevated for 3 weeks compared to those in the $N \operatorname{lrp} 3^{-/-} \mathrm{Nlrc} 4^{-/-}$mice (Fig. 4c, days 7-28) matching that of the serum IL-18 production. During the early stages of infection, cells such as natural killer cells are the main source of serum IFN- $\gamma^{30}$ explaining why at day $7 \mathrm{Nlrc} 4^{-/-}$mice have higher levels of IFN- $\gamma$ in the serum (Fig. 4c), but not when their $\mathrm{CD} 4^{+} \mathrm{T}$ cells are stimulated with bacterial extract ex vivo (Fig. 2a). Our data collectively indicate that, consistent with its role in downregulating $\mathrm{CD} 4^{+} \mathrm{T}$-cell memory responses, NLRC4 activation suppresses NLRP3-driven amplification of serum IL-18 and IFN- $\gamma$.

$S$. Typhimurium expressing flagellin from non-pathogenic $E$. coli evades NLRC4 recognition. Flagellin activates both TLR5 and NAIP/NLRC4 with the latter also recognizing Salmonella type III secretory proteins such as PrgJ. TLR5 is important for generating 


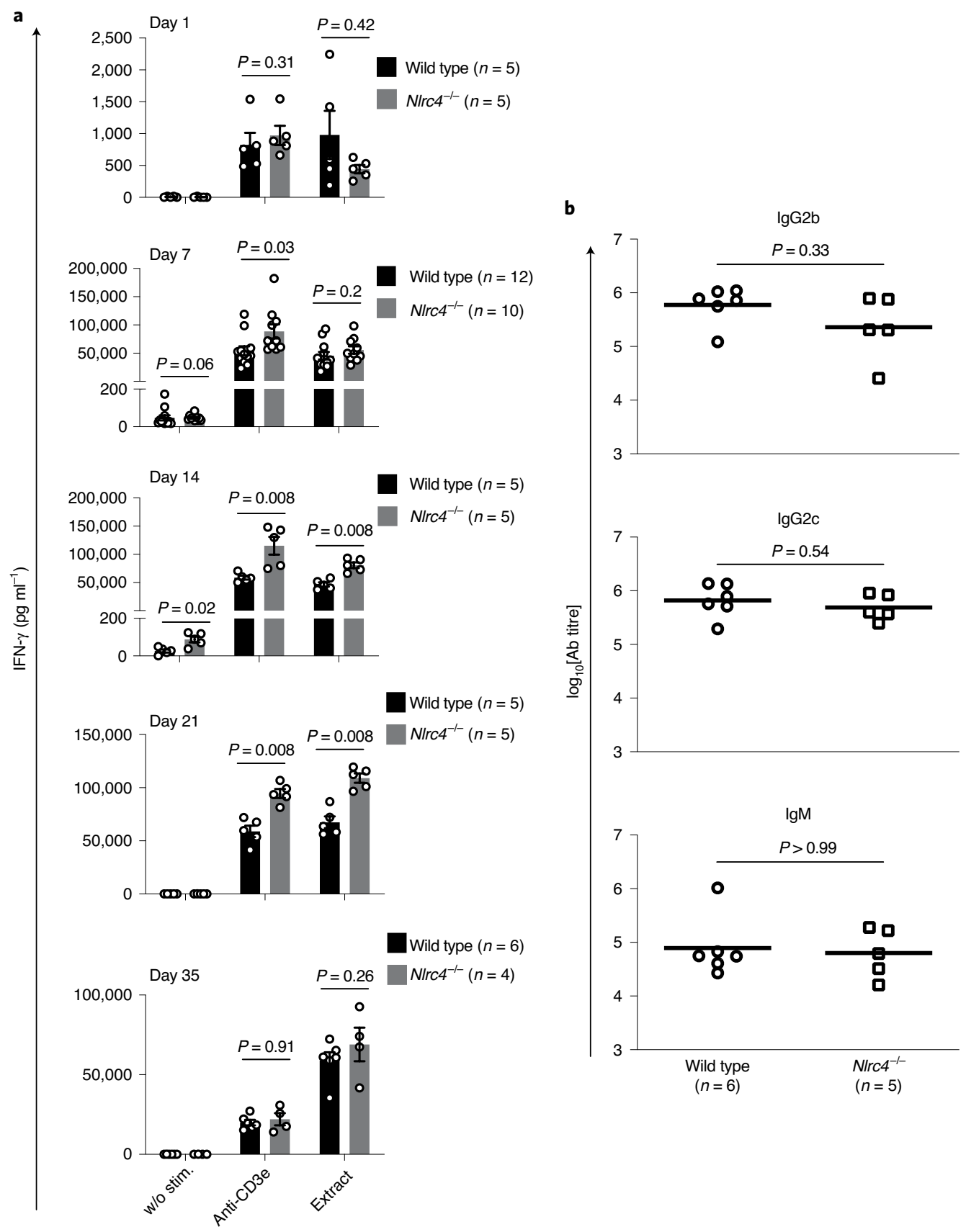

Fig. 2 | NLRC4 restricts the magnitude of effector CD4 ${ }^{+}$T-cell responses during microbial clearance of a primary infection. $\mathbf{a}$, Wild-type and N/rc $4^{-/-}$ mice were challenged i.v. with $7.2 \times 10^{3}-1 \times 10^{4}$ c.f.u. of S. Typhimurium M525P and T-cell-mediated responses were analysed over time. CD4+ $\mathrm{T}$ cells were cocultured ex vivo with feeder cells in the presence of medium only (w/o stim.), antimouse CD3e (anti-CD3e) or whole bacterial cell extract (extract) and IFN- $\gamma$ was measured by ELISA in the cell culture supernatant after $72 \mathrm{~h}$. b. Wild-type and N/rc $4^{-/-}$mice were challenged i.v. with $7 \times 10^{3}$ c.f.u. S. Typhimurium M525P and levels of IgG2b, IgG2c and IgM antibodies against $S$. Typhimurium LPS were measured in the serum at $90 \mathrm{~d}$ post-challenge via ELISA. Data are shown as mean \pm s.e.m. in $\mathbf{a}$. Each symbol represents one mouse with horizontal lines delineating the mean in $\mathbf{b}$. Statistical significance was assessed by a two-tailed Mann-Whitney test. Data are pooled from two independent experiments for $\mathbf{a}$, day 7 and generated from one experiment in a, days 1, 14, 21 and 35. Data are representative of two independent experiments for $\mathbf{b}$.

T-cell immunity against $S$. Typhimurium ${ }^{31}$, but our data indicate that NLRC4 downregulates CD4 ${ }^{+}$T-cell-mediated memory, while, at the same time, enhancing host survival during the early stages of a lethal infection (Extended Data Fig. 4a). We considered that primary challenge with Salmonella genetically engineered to partially evade recognition by NLRC4, by mutating rather than deleting fliC, should retain TLR5 activation, enhance memory immunity and, therefore, potentially increase resistance to lethal rechallenge.
We genetically modified the wild-type M525P strain, which naturally lacks $f l j B$, by replacing its native $f l i C$ with that from non-pathogenic E. coli K-12 substrain MG1655, to generate $S$. Typhimurium M525P $\Delta$ fliC::fliC ${ }_{\mathrm{MG} 1655}\left(\mathrm{M} 525 \mathrm{P} \mathrm{fliC}_{\mathrm{MG} 1655}\right.$ ). Comparison of the predicted FliC proteins from $S$. Typhimurium and E. coli K-12 MG1655 showed high sequence homology at the $\mathrm{N}$ - and C-terminal regions of the protein, but with a variable central domain (Extended Data Fig. 7). Flagellin from this E. coli strain 
a
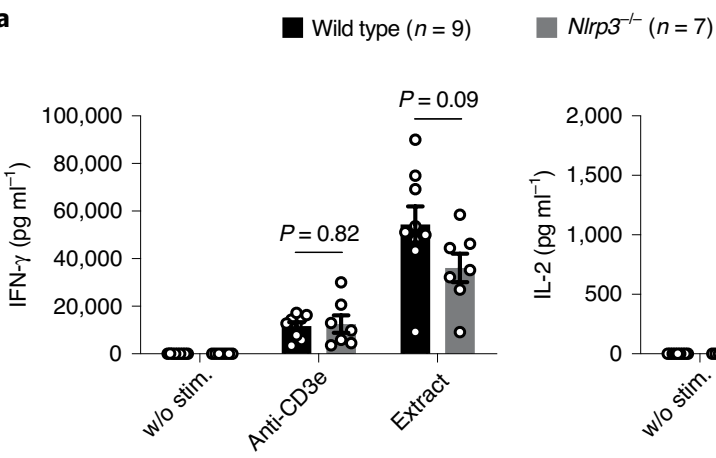

c

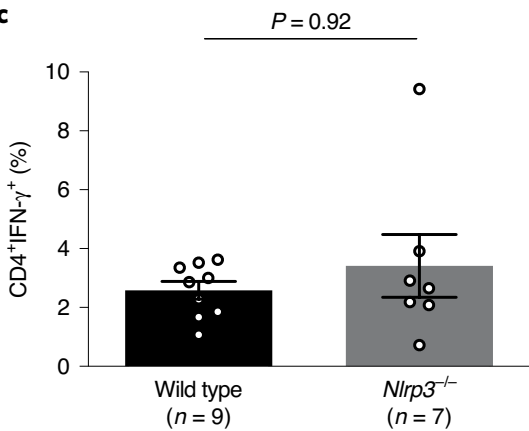

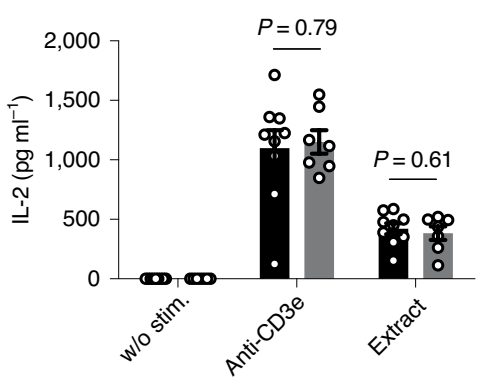

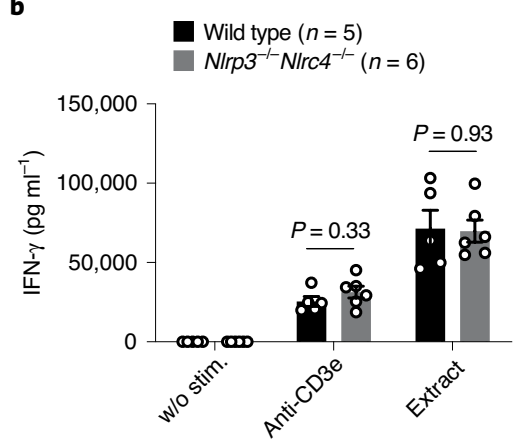

b

d

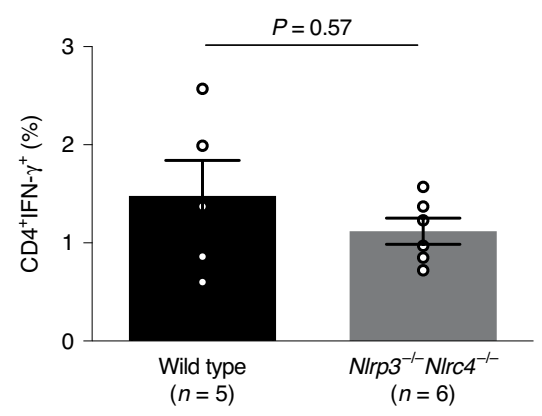

Fig. 3 | NLRC4 restricts the potency of CD4+ T-cell-mediated memory responses against Salmonella in a NLRP3-dependent manner. The Th1 memory response was assessed by stimulating $C D 4^{+} T$ cells ex vivo with medium only (w/o stim.), antimouse CD3e (anti-CD3e), or whole bacterial cell extract (extract). a, CD4+ T cells from wild-type and N/rp3 ${ }^{-/-}$mice $100 \mathrm{~d}$ after challenge with $2.2 \times 10^{4}$ c.f.u. S. Typhimurium M525P and IFN- $\gamma$ and IL-2 were measured by ELISA in the cell culture supernatant after 72 and $24 \mathrm{~h}$, respectively. b. CD4+ $4^{+}$cells from wild-type and N/rp3 ${ }^{-/-}$N/rc $4^{-/-}$mice $90 \mathrm{~d}$ after challenge with $1.72 \times 10^{4}$ c.f.u. S. Typhimurium M525P and IFN- $\boldsymbol{\gamma}$ was measured as in $\mathbf{a}$. c, Same experiment as a, the percentage of CD4+ T cells secreting IFN- $\gamma$ in response to bacterial extract was determined via a cytokine secretion assay. $\mathbf{d}$, Same experiment as $\mathbf{b}$, the percentage of CD4+ $T$ cells secreting IFN- $\gamma$ was determined via a cytokine secretion assay. Data are shown as mean \pm s.e.m. Statistical significance was calculated using a two-tailed, unpaired Student's $t$-test assuming equal variances for $\mathbf{a}$ and $\mathbf{c}$ and a two-tailed Mann-Whitney test for $\mathbf{b}$ and $\mathbf{d}$. All data are representative of two independent experiments.

activates TLR5 as efficiently as flagellin from $S$. Typhi but is impaired in activating NLRC4 (ref. ${ }^{32}$ ). M525P fliC $_{\mathrm{MG} 1655}$ also retains bacterial motility (Extended Data Fig. 8a), which may be important to facilitate infection and spread into the tissues. When tested in vitro, this mutant induced less cell death and IL- $1 \beta$ production than the wild-type strain in wild-type but not in $\mathrm{Nlrc4}^{-/-}$macrophages, but could still activate NAIP1/2-NLRC4 signalling presumably via its type III secretion system (Extended Data Fig. $8 \mathrm{~b}, \mathrm{c}$ ). TNF- $\alpha$ production by wild-type macrophages infected with M525P fliC $_{\mathrm{MG} 1655}$ or M525P were comparable (Extended Data Fig. 8d) suggesting no deficit in TLR activation. These data indicate that M525P fliC $_{\mathrm{MG}_{1655}}$ shows reduced, but not obliterated, NLRC4 inflammasome recognition.

Wild-type mice infected with M525P fli $_{\mathrm{MG} 1655}$ had a higher bacterial burden than those infected with M525P (Fig. 5a), comparable to that seen in $\mathrm{NlrC4}^{-/-}$mice challenged with M525P (Fig. 1a). Bacterial loads of M525P and M525P fliC $_{\mathrm{MG} 1655}$ were similar in $\mathrm{Nlrc}^{-/-}$mice confirming that the increased spread of M525P fli $_{\mathrm{MG} 1655}$ into the tissues was NLRC4-dependent (Fig. 5b). Serum levels of IL-18 and IFN- $\gamma$ were significantly increased for 2 weeks (Fig. 5c,d, day 7 to 21 ) in mice infected with M525P fli $C_{M G 1655}$ when compared to mice infected with M525P, again comparable to the differences seen between wild-type and $\mathrm{Nlrc}^{-/-}$mice infected with M525P (compare Fig. 4b,c with Fig. 5c,d). Infection of wild-type mice with M525P fliC ${ }_{\mathrm{MG} 1655}$ did not, however, induce as high levels, or as sustained production, of IL-18 as seen in $\mathrm{Nlrc4}^{-/-}$mice infected with M525P (compare Fig. 4b with Fig. 5c). This is consistent with M525P fliC $_{\mathrm{MG} 1655}$ retaining some residual capacity to activate NLRC4.
Primary challenge with $S$. Typhimurium M525P fliC $_{\mathrm{MG} 1655}$ enhances $\mathrm{CD}^{+} \mathrm{T}$-cell memory responses and improves protection against lethal rechallenge. We compared the $\mathrm{CD}^{+}{ }^{+} \mathrm{T}$-cell memory responses between wild-type mice challenged with M525P or M525P fliC $\mathrm{MG}_{\mathrm{MG55}}$ and found them to be higher in the M525P $\mathrm{fliC}_{\mathrm{MG} 1655}$ group (Fig. 6a), comparable to those seen in $\mathrm{Nlrc4}^{-/-}$ mice (Fig. 1c). To determine whether primary challenge with $S$. Typhimurium M525P fliC $_{\mathrm{MG1655}}$ would confer any resistance against lethal rechallenge, wild-type mice were systemically infected with $\mathrm{M} 525 \mathrm{P}$ or $\mathrm{M} 525 \mathrm{P} \mathrm{fliC}_{\mathrm{MG} 1655}$ and allowed to clear the infection before rechallenge with fully virulent SL1344. Mice initially infected with M525P survived for $8.5 \mathrm{~d}$ while the survival rate of mice infected with $\mathrm{M} 525 \mathrm{P}$ fli $\mathrm{C}_{\mathrm{MG} 1655}$ was markedly increased with approximately $75 \%$ of them surviving up to $21 \mathrm{~d}$ postlethal rechallenge (Fig. 6b). Mice in the M525P fli $\mathrm{C}_{\mathrm{MG} 1655}$ group also lost less weight from days 4 to 6 after rechallenge when compared to mice in the M525P group (Fig. 6c). These data indicate that reduced NLRC4 activation during primary challenge promotes protection against rechallenge, although the mechanism by which this occurs is unclear.

Increased levels of serum IL-18 correlated with increased effector immunity (Figs. $2 \mathrm{a}$ and $4 \mathrm{~b}$ ), we, therefore, tested whether IL-18 contributes to the amplification of $\mathrm{CD} 4^{+}$T-cell immunity seen when NLRC4 activation is impaired. We compared the ex vivo memory responses between wild-type and $I L-18^{-/-}$mice challenged with M525P and found no difference suggesting that, when NLRC4 is fully activated, IL-18 does not affect the potency of the response (Fig. 6d). When mice were challenged with 

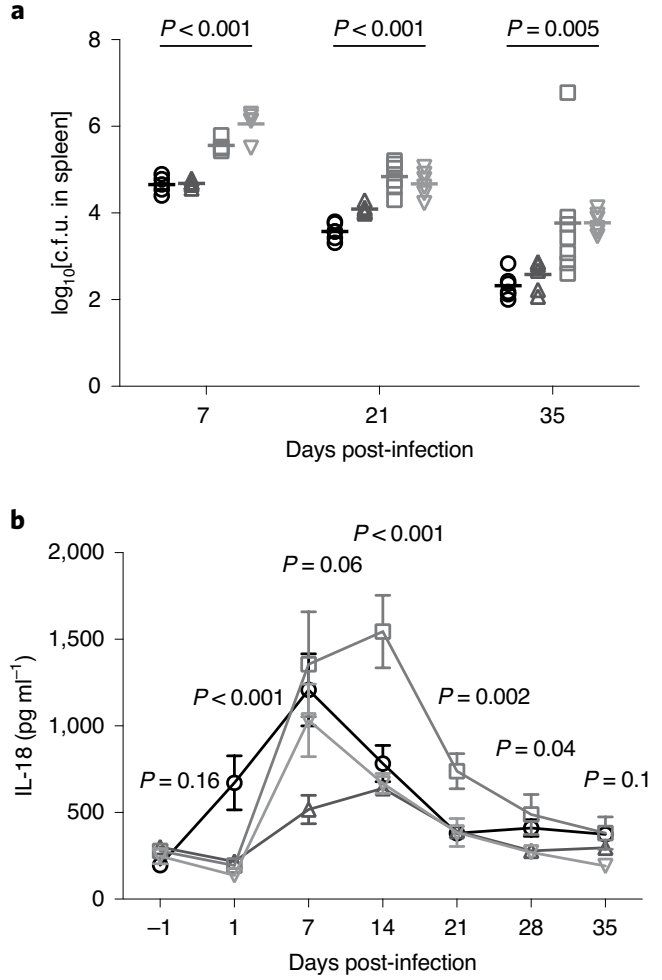
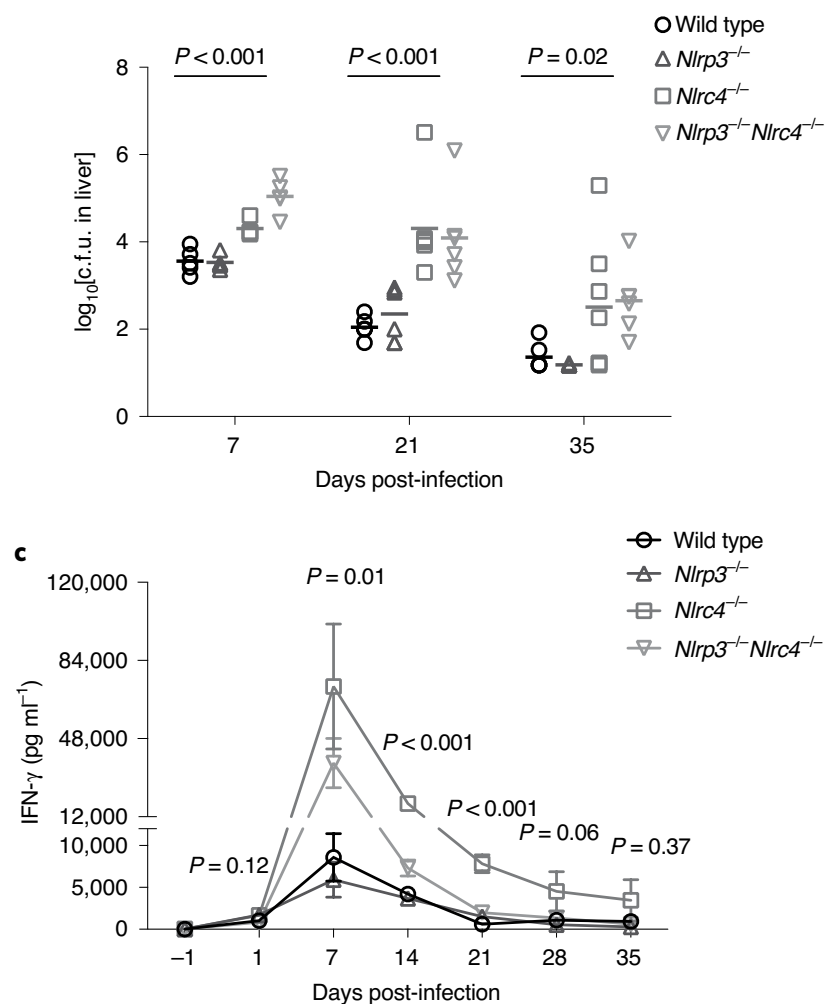

Fig. 4 | NLRC4 restricts NLRP3-dependent secretion of IL-18 and IFN- $\boldsymbol{\gamma}$. Wild-type, N/rp3 $3^{-/-}$, NIrc $4^{-/-}$and N/rp3 $3^{-/-}$NIrc4 ${ }^{-/-}$mice were challenged i.v. with $1.86 \times 10^{4}$ c.f.u. S. Typhimurium M525P. a, Bacteria were counted in the spleen and the liver at day 7 ( $n=5$ for wild-type, N/rp3 ${ }^{-/-}$and N/rp3-/-N/rc4-/- and $n=4$ for N/rc $\left.4^{-/-}\right), 21$ ( $n=6$ for all genotypes) and 35 ( $n=6$ for wild-type, N/rp3 ${ }^{-/-}$and N/rp3 ${ }^{-/-N / r c 4^{-/-}}$and $n=7$ for N/rc4 ${ }^{-/-}$) post-challenge. b, IL-18

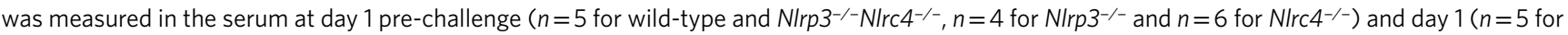
wild-type and $n=6$ for all other genotypes), 7 ( $n=5$ for wild-type, N/rp3 ${ }^{-/-}$and N/rp3 ${ }^{-/-N}$ Irc $4^{-/-}$and $n=4$ for N/rc4 ${ }^{-/-}$), 14 ( $n=6$ for wild-type and $n=5$ for

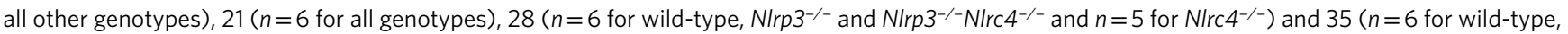
N/rp3 $3^{-/-}$and N/rp3 $3^{-/-N} \mathrm{Irc} 4^{-/-}$and $n=7$ for N/rc4 ${ }^{-/-}$) postchallenge by ELISA. c, IFN- $\gamma$ was measured by fluorescent bead immunoassay in the serum over time with the same number of mice as in $\mathbf{b}$ apart from day 1 pre-challenge ( $n=5$ for wild-type and $n=4$ for all other genotypes). Each symbol represents one mouse with horizontal lines delineating the mean in a. Data are shown as mean \pm s.e.m. in b,c. Overall statistical significance has been determined by a one-way ANOVA for each interval separately. For wild-type versus N/rc4 ${ }^{-/-}$mice, data are representative of three independent experiments. For wild-type versus $\mathrm{N} / r p 3^{-/-}$and $\mathrm{N} / \mathrm{rp} 3^{-/-} \mathrm{N} / \mathrm{rc} 4^{-/-}$mice, data are representative of two independent experiments.

M525P fli ${ }_{\mathrm{MG} 1655}$, however, the IFN $-\gamma$ response was reduced in $I L-18^{-/-}$ mice and, although this did not meet statistical significance (Fig. 6e, $P=0.0513$ ) is, nevertheless, suggestive of a link between NLRC4, IL-18 and CD4 ${ }^{+}$T-cell-mediated Th1 memory.

\section{Discussion}

Pathogen-mediated activation of PRRs should determine the specificity of, and enhance the production of, antigen-specific immunity, yet here we show that activation of the PRR NLRC4 supresses memory CD4 ${ }^{+}$T-cell-mediated responses against Salmonella. The CD4 ${ }^{+}$ T-cell-mediated immunity is critical for host control and long-term protection against intraphagosomal pathogens such as Salmonella. Equally important is the fact that mice initially challenged with a Salmonella strain that evades detection by NLRC4 were protected against an otherwise lethal rechallenge. This work, therefore, has important implications for vaccine development against pathogens that efficiently activate the NLRC4 inflammasome, such as Legionella $^{33}$, Pseudomonas ${ }^{34}$ and Shigella ${ }^{35}$.

We used inflammasome-deficient mice to show that activation of NLRC4 by $S$. Typhimurium curtails antigen-specific CD $4^{+}$ T-cell-mediated memory responses and confirmed this phenotype by using a Salmonella mutant defective in activating NLRC4. In the wild-type strain we replaced native flagellin with flagellin from E. coli that is impaired in activating NLRC4, but can still activate
TLR5 and keep the mutant motile, both of which could potentially affect the development of immunity against Salmonella. This mutant enhanced antigen-specific immunity, most probably by its clear ability to evade NLRC4 activation, but it would be interesting to test if a flagellin-deficient mutant would induce similar effects in vivo.

Relatively little is known about whether NLRC4 can affect the development of antigen-specific immunity against pathogens. Studies investigating the effect of NLRC4 on CD8 ${ }^{+}$T-cell immunity have shown contrasting results. Listeria monocytogenes constitutively expressing flagellin from Legionella pneumophila suppressed CD8 ${ }^{+}$ T-cell immunity in mice and failed to protect them against rechallenge ${ }^{36}$. Flagellin recognition by NLRC4 during Salmonella infection, in contrast, induces IFN- $\gamma$ release by memory $\mathrm{CD}^{+} \mathrm{T}$ cells ${ }^{19}$. A similar phenomenon has been described in Salmonella-induced CD4 ${ }^{+}$Th1 effector cells that require both NLRC4 and NLRP3 to optimally secrete IFN- $\gamma$ in response to LPS and flagellin ${ }^{18}$. Unlike our work, however, both these studies describe a role for NLRC4 in non-antigen-specific immune responses and suggest that NLRC4 activation drives the induction, rather than downregulation, of T-cell responses.

Our data show that NLRC4 activation negatively regulates $\mathrm{CD}^{+}{ }^{+}$T-cell-mediated memory immunity against Salmonella via an NLRP3-dependent mechanism. Salmonella engages first NLRC4 
a

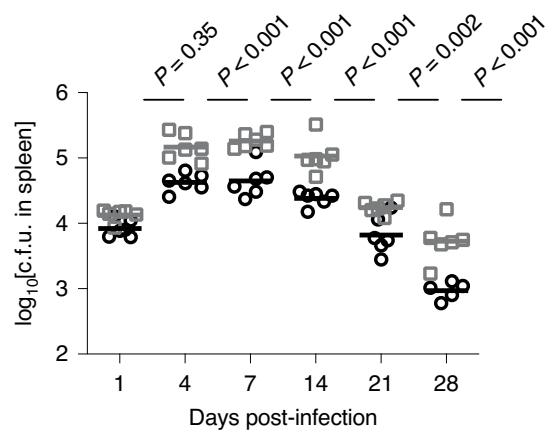

b
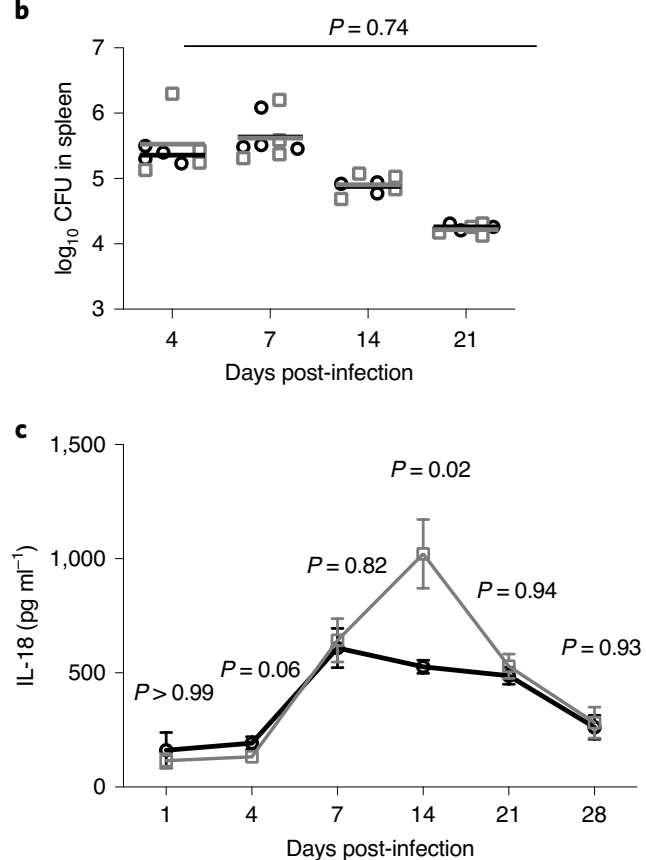
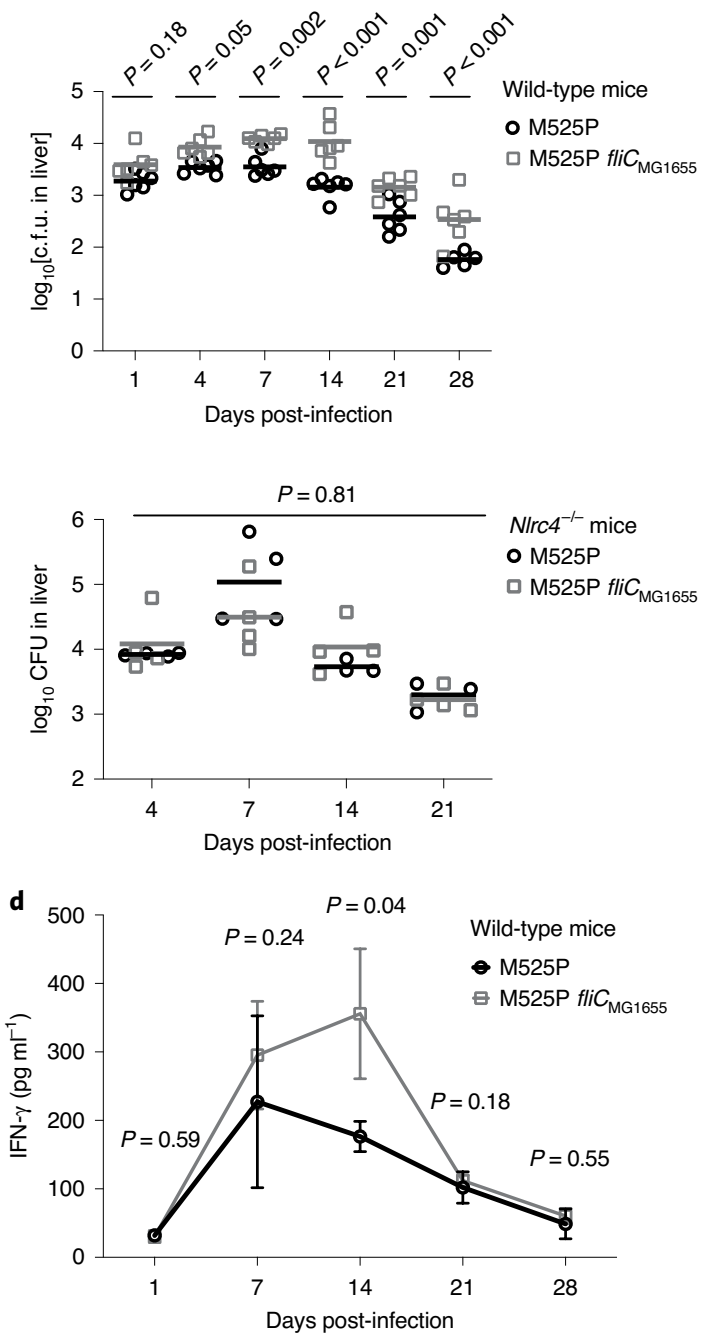

Fig. 5 | Salmonella expressing flagellin from non-pathogenic E. coli largely escapes NLRC4-mediated detection in vivo. Wild-type and N/rc4 ${ }^{-/-}$mice were challenged i.v. with $1.5 \times 10^{4}$ c.f.u. S. Typhimurium M525P or M525P fliC $\mathrm{MG}_{1655}$. a, Bacteria were counted in the spleen and the liver of wild-type mice over time ( $n=6$ for both groups for all days apart from day 35; $n=5$ for M525P and $n=6$ for M525P fliC $\mathrm{MG}_{1655}$ ). $\mathbf{b}$, Bacteria were counted in the spleen and the

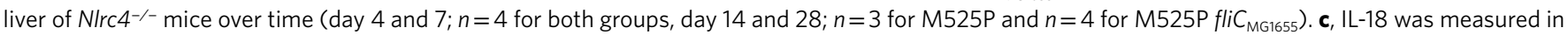
the serum of wild-type mice over time by ELISA with the same number of mice as in $\mathbf{a}$. $\mathbf{d}$, IFN- $\gamma$ was measured in the serum of wild-type mice over time by a fluorescent bead immunoassay with the same number of mice as in $\mathbf{a}$. Each symbol represents one mouse with horizontal lines delineate the mean in $\mathbf{a}, \mathbf{b}$. Data are shown as mean \pm s.e.m. in c,d. Statistical significance was calculated by a two-way ANOVA followed by Sidak's multiple comparisons tests in $\mathbf{a}$ and $\mathbf{b}$ and a two-tailed Mann-Whitney test for each time point separately in $\mathbf{c}$ and $\mathbf{d}$. All data are representative of two independent experiments.

and subsequently NLRP3, which maximizes IL-1 $1 /$ IL-18 production in vitro ${ }^{15,22}$ and is particularly important when NLRC4 activation is impaired. Our work shows that mice lacking NLRC4 have increased serum IL-18 levels only when they have functional NLRP3, while deficiency in both PRRs prevents IL-18 amplification in the serum. We propose that during $S$. Typhimurium infection, NLRC4 prevents NLRP3 from amplifying cytokine production by APCs and this, in turn, restricts the potency of pathogen-specific immune responses. Defective NLRC4 activation by increasing the levels of Th1-related cytokines in the serum enhances the expansion of antigen-specific $\mathrm{CD}^{+} \mathrm{T}$ cells and, consequently, this would give rise to a larger pool of memory cells. These cytokines could either be produced by the APCs during their interaction with naive $\mathrm{T}$ cells or by cells other than APCs at a later stage to act on activated effector T cells ${ }^{4}$.

The NLRP3-dependent mechanism by which NLRC4 suppresses T-cell memory responses is unclear but our data indicate that IL-18 could be important. IL-18 enhances Th1 antigen-specific immunity by increasing IFN $\gamma$ production from Th1 $\mathrm{CD}^{+} \mathrm{T}$ cells and natural killer cells ${ }^{37}$. It is also important for the maintenance of potent Th1 responses against Listeria $^{38}$ and promotes antigen-specific clonal expansion and survival of effector $\mathrm{CD}^{+} \mathrm{T}$ cells in response to flagellin ${ }^{39}$. In our model, elevated serum IL-18 coincides with increased $\mathrm{CD}^{+}{ }^{+} \mathrm{T}$-cell effector responses and persists for two to three weeks during the microbial clearance phase when most effector cells die and only a small fraction survive to become quiescent, long-lived memory cells ${ }^{40}$. We saw that when NLRC4 activation is defective, IL-18 deficiency partially prevents the amplification of memory responses. Other mechanisms may be important, however, such as the production of IL- $1 \beta$ that can enhance Th1 cell expansion $^{41}$ or cytokine-independent mechanisms, such as phagosome acidification, which can affect the development of adaptive immunity against Gram-positive bacteria ${ }^{42}$.

In conclusion, here we describe an unknown mechanism by which reduced activation of a PRR, NLRC4, enhances antigen-specific 
a

$\operatorname{M525P}(n=8) \quad$ M525P fliC $C_{\text {MG1655 }}(n=8)$

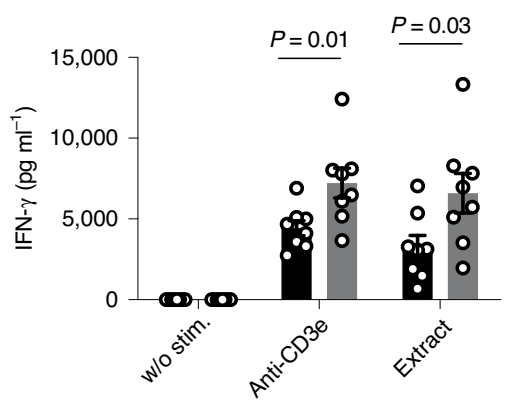

b

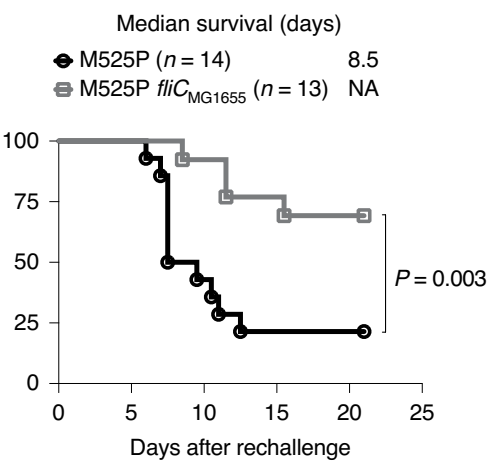

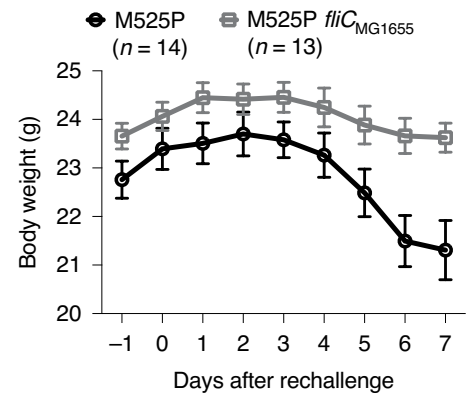

d

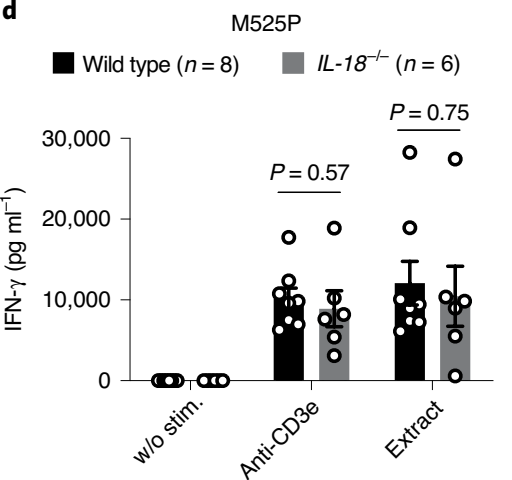

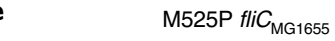

Wild type $(n=6) \quad I L-18^{-/-}(n=7)$

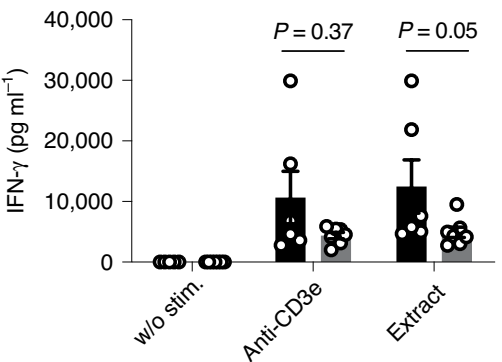

Fig. 6 | Primary challenge with Salmonella expressing flagellin from non-pathogenic $E$. coli improves protection against lethal rechallenge. a, CD4+

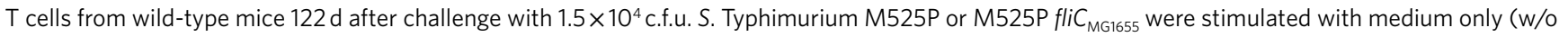
stim.), antimouse CD3e (anti-CD3e) or whole bacterial cell extract (extract). IFN- $\gamma$ was measured by ELISA in the cell culture supernatant after $24 \mathrm{~h}$. b, Wild-type mice were challenged with $1.6 \times 10^{4}$ c.f.u. S. Typhimurium M525P or $1.5 \times 10^{4}$ c.f.u. M525P fliC MG1655 $_{\text {and }}$ allowed to clear the primary infection for $128 \mathrm{~d}$. They were then rechallenged orally with $4.8 \times 10^{6}$ c.f.u. S. Typhimurium SL1344 and euthanized on detection of adverse signs. NA, not applicable. c, In the same experiment as in $\mathbf{b}$, mouse weight was recorded at least once daily and shown for the first $7 \mathrm{~d}$ of infection. $\mathbf{d}$, CD4+ $\mathrm{T}$ cells obtained from wild-type and $I L-18^{-/-}$mice $104 \mathrm{~d}$ after primary challenge with $1.6 \times 10^{4}$ c.f.u. S. Typhimurium M525P were stimulated and IFN- $\gamma$ was measured as in a.

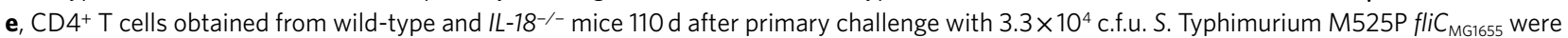
stimulated and IFN- $\gamma$ was measured as in $\mathbf{a}$. Data are shown as mean \pm s.e.m. in $\mathbf{a}, \mathbf{c}-\mathbf{e}$ and as a survival curve in $\mathbf{b}$. Statistical significance was calculated by a two-tailed Mann-Whitney test in $\mathbf{a}$, $\mathbf{d}$ and $\mathbf{e}$ and a two-sided log-rank in $\mathbf{b}$. Data are representative of two independent experiments for $\mathbf{a}$ and were generated from one experiment for $\mathbf{b}-\mathbf{e}$.

memory responses and promotes long-term protection against rechallenge. This reveals a clear link between NLRC4 activation and restriction of pathogen-specific immunity within a physiological setting. Whether this phenomenon is induced by the pathogen as a strategy to impede the development of optimal memory responses or by the host to avoid immunopathology by tightly regulating levels of proinflammatory cytokines remains to be determined.

\section{Methods}

Mice. Wild-type C57BL/6J mice were obtained from Charles River. Nlrc4 ${ }^{-1-}$ and $N \operatorname{lrp} 3^{-/-}$mice on a C57BL/6J background (after at least eight back crosses onto the C57BL/6J background) were kindly provided by K. Fitzgerald (University of Massachusetts Medical School). The Nlrc4 $4^{-/-} \mathrm{Nlrp3}^{-/-}$mice were generated in-house by crossing $\mathrm{Nlrc}^{-/-}$with $\mathrm{Nlrp3^{-/- }}$ mice. All mouse colonies were bred independently. Mice were genotyped by PCR using standard protocols. All mice were maintained in a specific pathogen-free facility according to the Animals Scientific Procedures outlined by the UK Home Office regulations. All work involving live animals complied with the University of Cambridge Ethics Committee regulations and was performed under the Home Office Project Licence numbers 80/2572 and P48B8DA35. Both male and female mice between 8 and 24 weeks of age were used in infection trials and as donors for primary bone marrow-derived macrophages (BMDMs).

Bacterial strains and animal infections. S. Typhimurium strains SL1344 and M525 ${ }^{43}$, strains of high and intermediate virulence, respectively, were used in this study. For in vitro studies, $S$. Typhimurium was grown from single colonies to exponential phase, by inoculating a $17.5 \mathrm{~h}$ overnight culture 1 in 10 into LB medium and incubating at $37^{\circ} \mathrm{C}, 200$ r.p.m. for $2 \mathrm{~h}$. For in vivo infections, stationary phase $S$. Typhimurium cultures were washed and resuspended in Dulbecco's PBS (D-PBS, Sigma). For i.v. challenge experiments, $0.2 \mathrm{ml}$ of the inoculum were administered systemically via the lateral tail vein. For oral challenge experiments, mice were lightly anaesthetized with isoflurane and then inoculated with $0.2 \mathrm{ml}$ of the inoculum via oral gavage. Control mice were inoculated with sterile PBS only. The exact dose of Salmonella administered was determined by serial dilution and plating the inoculum on LB plates before and after infection. Primary challenge in all experiments was performed by i.v. administration of approximately $10^{4}$ c.f.u. S. Typhimurium 525P wild-type or mutant per mouse unless mentioned otherwise. Exact doses for each experiment are given in the legends of the respective graphs. All experiments were performed after approval from the University of Cambridge ethical review committee and under the UK Government Home Office regulations licence numbers 80/2135, 80/11763, PF86EABB1 and P48B8DA35. In this work, no statistical methods were used to predetermine the sample size. The experiments were not randomized, and the investigators were not blinded to allocation during the experiments and outcome assessments.

Humane endpoint curves. In animal trials that involved rechallenge with fully virulent $S$. Typhimurium, we constructed humane endpoint curves as an alternative to survival curves. To do this, mice were weighed once and assessed twice daily for manifestation of clinical signs associated with generalized infection. These include weight loss of over $15 \%$ of maximum body weight, marked piloerection, subdued behavioural pattern even when provoked and reduced exploration, isolation from peers, intermittent hunched posture and persistent 
oculo-nasal discharge. Mice would be euthanized without delay when any of these signs persisted for more than $12 \mathrm{~h}$

Bacterial isolation and enumeration. Mice were euthanized at specific intervals following infection and their spleens and livers removed aseptically. Organs were homogenized in $10 \mathrm{ml}$ sterile water using a Colworth stomacher. Organ homogenates were serially diluted and plated on LB agar plates. LB plates were incubated overnight at $37^{\circ} \mathrm{C}$ followed by enumeration of c.f.u. In some experiments, spleens were first passed through a cell strainer to produce single cell suspensions in RPMI medium, a fraction of which was then used for bacterial enumeration.

Construction of $S$. Typhimurium M525P $\Delta$ fliC:: $f l i C_{E . c o l i}$ and bacterial motility assays. To engineer $S$. Typhimurium that expresses the FliC protein of the non-pathogenic E. coli K-12 strain MG1655, a DNA fragment was synthesized by GeneArt Gene Synthesis (Life Technologies) encoding E. coli K-12 MG1655 fliC adjacent to a chloramphenicol resistance cassette $\left(\mathrm{Cm}^{\mathrm{R}}\right)$ and flanked by $60 \mathrm{bp}$ arms homologous to the sequence immediately upstream and downstream of $S$. Typhimurium M525P fliC. This $\mathrm{fli}_{\mathrm{MG} 1655}$ cassette was transformed into electrocompetent $S$. Typhimurium M525P cells carrying the pBAD $\lambda$ Red plasmid ${ }^{44,45}$. Transformants were selected on LB agar supplemented with $25 \mu \mathrm{g} \mathrm{ml}^{-1}$ of chloramphenicol and positive clones were confirmed by sequencing. The growth rate of the mutant strain was assessed by performing viable bacterial counts and found to be similar to that of the wild-type strain (Supplementary Fig. 1).

To assess bacterial motility, overnight cultures grown in LB medium were diluted into fresh $\mathrm{LB}$ medium to an optical density $\left(\mathrm{OD}_{600}\right)$ of 0.05 and grown at $37^{\circ} \mathrm{C}$ until cultures reached an $\mathrm{OD}_{600}$ of 1.0. Two microlitres of culture were inoculated into $0.25 \%$ tryptone agar $\left(2.5 \mathrm{gl}^{-1}\right.$ of agar, $10 \mathrm{gl}^{-1}$ of tryptone, $5 \mathrm{gl}^{-1}$ of $\left.\mathrm{NaCl}\right)$. Plates were incubated at $37^{\circ} \mathrm{C}$ for between 4 and $6 \mathrm{~h}$ and swarm diameter was measured.

Cell culture and infections. BMDMs were prepared as previously described ${ }^{15}$. They were infected with $S$. Typhimurium grown to exponential phase as previously described $^{46}$. Cell viability was assessed using the Cytotox 96 Non-Radioactive Cytotoxicity assay (Promega)

$\mathrm{CD4}^{+} \mathrm{T}$-cell ex vivo stimulation assays. Mice were euthanized, their spleens aseptically removed and, after mechanical disruption, passed through a $70-\mu \mathrm{m}$ cell strainer (BD Biosciences) to obtain single cell suspensions in prewarmed RPMI containing 2\% (vol/vol) FCS (Hyclone). Cell suspensions were washed once and resuspended in Red Blood Cell Lysis buffer (Sigma), mixed and incubated for $10 \mathrm{~min}$ on ice. Total splenocytes were washed twice and passed through a $30-\mu \mathrm{m}$ filter (Partec). CD4 ${ }^{+} \mathrm{T}$ cells were purified using CD4 microbeads and magnetic positive selection according to the manufacturer's guidelines (Miltenyi Biotec). This routinely resulted in cell populations containing over $95 \% \mathrm{CD}^{+}$ cells. CD4 ${ }^{+} \mathrm{T}$ cells were resuspended in complete RPMI medium containing

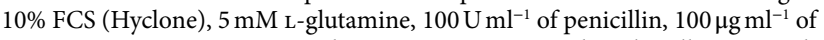
streptomycin, $1 \mathrm{mM}$ HEPES and $0.02 \mathrm{mM} \beta$-mercaptoethanol. Cells were seeded at $2 \times 10^{5}$ cells per well in round bottom 96-well plates (Greiner Bio-One) together with wild-type naïve total splenocytes previously treated $\left(1 \mathrm{~h}\right.$ at $37^{\circ} \mathrm{C}$ and $5 \% \mathrm{CO}_{2}$ ) with Mitomycin C $25 \mu \mathrm{g} \mathrm{ml}^{-1}$ (Sigma) at a 1:1 ratio (total cell number of $4 \times 10^{5}$ cells per well). Cocultures from each mouse were left unstimulated, stimulated with $2 \mu \mathrm{g} \mathrm{ml}^{-1}$ antimouse CD3e (clone 145-2C11, eBioscience) or $20 \mu \mathrm{g} \mathrm{ml}^{-1}$ whole Salmonella cell extract, prepared as described previously ${ }^{47}$ and incubated at $37^{\circ} \mathrm{C}$ and $5 \% \mathrm{CO}_{2}$. In some experiments, the polyclonal stimulus was provided by concanavalin A (rather than antimouse CD3e), which was used at a final concentration of $5 \mu \mathrm{g} \mathrm{ml}^{-1}$. Cell culture supernatants were collected after 24 and $72 \mathrm{~h}$ incubation for cytokine quantification.

When $\mathrm{CD}^{+}{ }^{+} \mathrm{T}$ Cells were stimulated ex vivo to assess memory immunity, it was important to confirm that the primary infection has cleared and the effector immune response subsided. For this reason, any mice whose microbial load was above detection limit ( 20 c.f.u. for the spleen and 10 c.f.u. for the liver) were not included in the study.

ELISpot and cytokine secretion assay. The numbers of CD4 ${ }^{+} \mathrm{T}$ cells secreting IFN- $\gamma$ were assessed by ELISpot and cytokine secretion assays. For ELISpot, capture and detection antibodies supplied by the mouse IFN- $\gamma$ ELISpot Development Module (R\&D Systems) were used according to the manufacturer's guidelines. Briefly, cocultures of purified $\mathrm{CD} 4^{+} \mathrm{T}$ cells with syngeneic feeder cells were incubated in duplicate wells in the presence or absence of whole Salmonella cell extract for $12 \mathrm{~h}$. Cell suspensions were then transferred in twofold serial dilutions to a capture antibody-coated 96-well filtration plate (Millipore) and incubated for a further $12 \mathrm{~h}$. ELISpot Blue Colour Module (R\&D Systems) analysis of the cell supernatant was performed according to the manufacturer's guidelines. Data were expressed as IFN- $\gamma$ spot-forming cells per $10^{6}$ cells. The number of $\mathrm{CD}^{+} \mathrm{T}$ cells secreting IFN- $\gamma$ was also determined using a flow cytometry-based cytokine secretion assay (Miltenyi Biotec) according to the manufacturer's guidelines. To reduce non-specific background staining and increase sensitivity, cells were simultaneously stained with a fixable viability dye and antimouse CD4 antibody (clone GK1.5) (both from Invitrogen) while the sequential gating strategy used is shown in Supplementary Fig. 2. Data from 100,000 viable cells were acquired from each mouse using a DxP Multi-color updated FACSCan (BD) analysed with FlowJo Software (TreeStar). In subsequent experiments, cells were also stained with antimouse CD44 (clone IM7) and CD62L (clone MEL-14) during cytokine secretion assay to better characterize the class of memory $\mathrm{CD} 4^{+} \mathrm{T}$ cells secreting IFN- $\gamma$ (effector or central memory). The sequential gating strategy for these analyses is shown in Extended Data Fig. 3. In this case, data from 100,000 viable cells were acquired from each mouse using an Attune NxT Flow Cytometer (Invitrogen) and analysed with FlowJo Software (TreeStar).

Enzyme-linked immunosorbent assay (ELISA) and multiplex immunoassays for cytokine quantification. Cytokine levels were measured in the serum and cell culture supernatant by bead-based, multiple cytokine detection immunoassay and/or ELISA analysis. Mouse serum was analysed via ELISA for levels of IL-1 $\beta$ (BD OptEIA set) and IL-18 (MBL International) and via multiplex immunoassays (ProcartaPlex, Invitrogen) for IFN- $\gamma$ and TNF- $\alpha$. Cell culture supernatant collected from the $\mathrm{CD}^{+} \mathrm{T}$-cell stimulation assays was analysed by ELISA for levels of IFN- $\gamma$ and IL-2 (DuoSet Development kit, R\&D Systems) and a flow cytometric, bead-based immunoassay (FlowCytomix, ebioscience) for simultaneous detection of mouse GM-CSF, IL- 6 and TNF- $\alpha$. IL- $1 \beta$ production from BMDMs infected with Salmonella was also analysed by ELISA. ELISAs and multiplex immunoassays were performed according to the manufacturer's guidelines.

Detection of serum anti-LPS antibodies. Antibody $(\mathrm{Ab})$ titres against $S$. Typhimurium LPS were measured in the serum of infected and control mice by ELISA as previously described ${ }^{48}$. Serum Ab titres were calculated on the basis a standard curve constructed by twofold serial dilutions of the same positive serum sample run on every plate. The dilution at which $\mathrm{OD}_{450}-\mathrm{OD}_{570}$ of the standard sample approximated the value of 1 was arbitrarily appointed as 1,000 $\mathrm{U}$.

Statistical analyses. All statistical analyses were performed with GraphPad Prism v.8 with each specific analysis described in the appropriate figure legend. Exact $P$ values are shown on each graph separately with $P<0.05$ considered statistically significant.

Reporting Summary. Further information on research design is available in the Nature Research Reporting Summary linked to this article.

\section{Data availability}

All data used to generate the figures presented in this work are available in Cambridge Research Repository Apollo with the identifier https://doi. org/10.17863/CAM.41575. Source data are provided with this paper.

Received: 8 July 2019; Accepted: 17 September 2020;

Published online: 26 October 2020

\section{References}

1. Takeda, K. \& Akira, S. Toll-like receptors. Curr. Protoc. Immunol. 109, 14.12.1-14.12.10 (2015)

2. Gross, O., Thomas, C. J., Guarda, G. \& Tschopp, J. The inflammasome: an integrated view. Immunol. Rev. 243, 136-151 (2011).

3. Iwasaki, A. \& Medzhitov, R. Control of adaptive immunity by the innate immune system. Nat. Immunol. 16, 343-353 (2015).

4. Evavold, C. L. \& Kagan, J. C. How inflammasomes inform adaptive immunity. J. Mol. Biol. 430, 217-237 (2018).

5. McSorley, S. J., Cookson, B. T. \& Jenkins, M. K. Characterization of CD4 ${ }^{+}$ $\mathrm{T}$ cell responses during natural infection with Salmonella typhimurium. J. Immunol. 164, 986-993 (2000).

6. Miao, E. A. et al. Cytoplasmic flagellin activates caspase-1 and secretion of interleukin 1 beta via Ipaf. Nat. Immunol. 7, 569-575 (2006).

7. Franchi, L. et al. Cytosolic flagellin requires Ipaf for activation of caspase-1 and interleukin 1 beta in salmonella-infected macrophages. Nat. Immunol. 7, 576-582 (2006).

8. Miao, E. A. et al. Innate immune detection of the type III secretion apparatus through the NLRC4 inflammasome. Proc. Natl Acad. Sci. USA 107, 3076-3080 (2010).

9. Lightfield, K. L. et al. Critical function for Naip5 in inflammasome activation by a conserved carboxy-terminal domain of flagellin. Nat. Immunol. $\mathbf{9}$, 1171-1178 (2008).

10. Zhao, Y. et al. The NLRC4 inflammasome receptors for bacterial flagellin and type III secretion apparatus. Nature 477, 596-600 (2011).

11. Kofoed, E. M. \& Vance, R. E. Innate immune recognition of bacterial ligands by NAIPs determines inflammasome specificity. Nature 477, 592-595 (2011).

12. Martinon, F., Burns, K. \& Tschopp, J. The inflammasome: a molecular platform triggering activation of inflammatory caspases and processing of proIL-beta. Mol. Cell 10, 417-426 (2002).

13. Broz, P. \& Dixit, V. M. Inflammasomes: mechanism of assembly, regulation and signalling. Nat. Rev. Immunol. 16, 407-420 (2016). 
14. Ding, J. \& Shao, F. Growing a gasdermin pore in membranes of pyroptotic cells. EMBO J. 37, e100067 (2018).

15. Man, S. M. et al. Inflammasome activation causes dual recruitment of NLRC4 and NLRP3 to the same macromolecular complex. Proc. Natl Acad. Sci. USA 111, 7403-7408 (2014)

16. Qu, Y. et al. NLRP3 recruitment by NLRC4 during Salmonella infection. J. Exp. Med. 213, 877-885 (2016)

17. Garlanda, C., Dinarello, C. A. \& Mantovani, A. The interleukin-1 family: back to the future. Immunity 39, 1003-1018 (2013).

18. O'donnell, H. et al. Toll-like receptor and inflammasome signals converge to amplify the innate bactericidal capacity of T helper 1 cells. Immunity $\mathbf{4 0 ,}$ 213-224 (2014).

19. Kupz, A. et al. NLRC4 inflammasomes in dendritic cells regulate noncognate effector function by memory CD8(+) T cells. Nat. Immunol. 13 162-169 (2012).

20. Hess, J., Ladel, C., Miko, D. \& Kaufmann, S. H. E. Salmonella typhimurium aroA- infection in gene-targeted immunodeficient mice - major role of CD4(+) TCR-alpha beta cells and IFN-gamma in bacterial clearance independent of intracellular location. J. Immunol. 156, 3321-3326 (1996).

21. Nauciel, C. Role of Cd4+ T-cells and T-independent mechanisms in acquired-resistance to Salmonella-Typhimurium infection. J. Immunol. 145, 1265-1269 (1990).

22. Broz, P. et al. Redundant roles for inflammasome receptors NLRP3 and NLRC4 in host defense against Salmonella. J. Exp. Med. 207, 1745-1755 (2010).

23. Lara-Tejero, M. et al. Role of the caspase-1 inflammasome in Salmonella typhimurium pathogenesis. J. Exp. Med. 203, 1407-1412 (2006).

24. Mastroeni, P., Simmons, C., Fowler, R., Hormaeche, C. E. \& Dougan, G. Igh- $6^{-1-}$ (B-cell-deficient) mice fail to mount solid acquired resistance to oral challenge with virulent Salmonella enterica serovar Typhimurium and show impaired Th1 T-cell responses to Salmonella antigens. Infect. Immun. 68, 46-53 (2000).

25. Heng, T. S. P., Painter, M. W. \& Project, I. G. The immunological genome project: networks of gene expression in immune cells. Nat. Immunol. 9, 1091-1094 (2008).

26. Bruchard, M. et al. The receptor NLRP3 is a transcriptional regulator of TH2 differentiation. Nat. Immunol. 16, 859-870 (2015).

27. Mariathasan, S. et al. Differential activation of the inflammasome by caspase-1 adaptors ASC and Ipaf. Nature 430, 213-218 (2004).

28. Tsutsui, H., Matsui, K., Okamura, H. \& Nakanishi, K. Pathophysiological roles of interleukin-18 in inflammatory liver diseases. Immunol. Rev. 174, 192-209 (2000).

29. Mastroeni, P., Villarreal-Ramos, B. \& Hormaeche, C. E. Role of T cells, TNF alpha and IFN gamma in recall of immunity to oral challenge with virulent salmonellae in mice vaccinated with live attenuated Aro-Salmonella. Vaccines. Micro. Pathogenesis 13, 477-491 (1992).

30. Kupz, A. et al. Contribution of Thy $1^{+}$NK cells to protective IFN-gamma production during Salmonella typhimurium infections. Proc. Natl Acad. Sci. USA 110, 2252-2257 (2013).

31. Letran, S. E. et al. TLR5-deficient mice lack basal inflammatory and metabolic defects but exhibit impaired CD4 T cell responses to a flagellated pathogen. J. Immunol. 186, 5406-5412 (2011).

32. Yang, J. et al. Flagellins of Salmonella Typhi and nonpathogenic Escherichia coli are differentially recognized through the NLRC4 pathway in macrophages. J. Innate Immun. 6, 47-57 (2014).

33. Amer, A. et al. Regulation of Legionella phagosome maturation and infection through flagellin and host Ipaf. J. Biol. Chem. 281, 35217-35223 (2006)

34. Franchi, L. et al. Critical role for Ipaf in Pseudomonas aeruginosa-induced caspase-1 activation. Eur. I. Immunol. 37, 3030-3039 (2007).

35. Suzuki, T. et al. Differential regulation of caspase- 1 activation, pyroptosis, and autophagy via Ipaf and ASC in Shigella-infected macrophages. PLoS Pathog. 3, e111 (2007).

36. Sauer, J. D. et al. Listeria monocytogenes engineered to activate the Nlrc4 inflammasome are severely attenuated and are poor inducers of protective immunity. Proc. Natl Acad. Sci. USA 108, 12419-12424 (2011).

37. Yoshimoto, T. et al. IL-12 up-regulates IL-18 receptor expression on T cells, Th1 cells, and B cells: synergism with IL-18 for IFN-gamma production. J. Immunol. 161, 3400-3407 (1998).
38. Neighbors, M. et al. A critical role for interleukin 18 in primary and memory effector responses to Listeria monocytogenes that extends beyond its effects on Interferon gamma production. J. Exp. Med. 194, 343-354 (2001).

39. Maxwell, J. R. et al. IL-18 bridges innate and adaptive immunity through IFN-gamma and the CD134 pathway. J. Immunol. 177, 234-245 (2006).

40. Pepper, M. \& Jenkins, M. K. Origins of CD4 ${ }^{+}$effector and central memory T cells. Nat. Immunol. 12, 467-471 (2011).

41. Ben-Sasson, S. Z. et al. IL-1 acts directly on CD4 T cells to enhance their antigen-driven expansion and differentiation. Proc. Natl Acad. Sci. USA 106, 7119-7124 (2009).

42. Sokolovska, A. et al. Activation of caspase-1 by the NLRP3 inflammasome regulates the NADPH oxidase NOX2 to control phagosome function. Nat. Immunol. 14, 543-553 (2013).

43. Mastroeni, P. et al. Antimicrobial actions of the NADPH phagocyte oxidase and inducible nitric oxide synthase in experimental salmonellosis. II Effects on microbial proliferation and host survival in vivo. J. Exp. Med. 192, 237-247 (2000).

44. Datsenko, K. A. \& Wanner, B. L. One-step inactivation of chromosomal genes in Escherichia coli K-12 using PCR products. Proc. Natl Acad. Sci. USA 97, 6640-6645 (2000).

45. Mo, E., Peters, S. E., Willers, C., Maskell, D. J. \& Charles, I. G. Single, double and triple mutants of Salmonella enterica serovar Typhimurium $\operatorname{deg} P(h \operatorname{tr} A)$, $\operatorname{deg} Q(h h o A)$ and $\operatorname{deg} S(h h o B)$ have diverse phenotypes on exposure to elevated temperature and their growth in vivo is attenuated to different extents. Micro. Pathog. 41, 174-182 (2006).

46. Man, S. M. et al. Salmonella infection induces recruitment of Caspase-8 to the inflammasome to modulate IL-1 beta production. J. Immunol. 191, 5239-5246 (2013).

47. Harrison, J. A., Villarreal-Ramos, B., Mastroeni, P., DeHormaeche, R. D. \& Hormaeche, C. E. Correlates of protection induced by live Aro(-) Salmonella Typhimurium vaccines in the murine typhoid model. Immunology $\mathbf{9 0}$, 618-625 (1997).

48. Dehormaeche, R. D., Jessop, H. \& Bundell, C. Antibodies to the C epitope of Neisseria gonorrhoeae are present in patients with gonorrhea and absent in normal sera. J. Gen. Microbiol. 134, 1289-1297 (1988).

\section{Acknowledgements}

This work was supported by grants from Biotechnology and Biological Sciences Research Council (BBSRC) (nos. BB/H003916/1 and BB/K006436/1), Zoetis UK (no. BB/ K006436/1) and Wellcome Trust (no. 108045/Z/15/Z) to C.E.B. A.S.B was supported by a Wellcome Trust 4-year PhD studentship. We thank K. A. Fitzgerald and D. Golenbock for suppling the gene-deficient mouse strains, S. M. Man for critical review of the manuscript and helpful discussions, and A. Cooke and members of her group, especially P. Zaccone and S. Newland, for sharing their expertise with P.T. and helpful discussions.

\section{Author contributions}

P.T. designed, performed and analysed all in vivo, ex vivo and in vitro experiments. P.M., J.A.W., L.J.H., A.S.B. and S.J.W performed part of some in vivo experiments. O.J.B. performed the bacterial motility assays. J.A.W supervised all bacterial mutagenesis work. A.S.B. performed all bacterial mutagenesis work. P.M., D.J.M. and C.E.B. conceived the study and secured the funding. C.E.B. and P.T. supervised the study. P.T., J.A.W. and C.E.B. wrote the manuscript.

\section{Competing interests}

The authors declare no competing interests.

\section{Additional information}

Extended data is available for this paper at https://doi.org/10.1038/s41564-020-00801-y. Supplementary information is available for this paper at https://doi.org/10.1038/ s41564-020-00801-y.

Correspondence and requests for materials should be addressed to C.E.B

Reprints and permissions information is available at www.nature.com/reprints. Publisher's note Springer Nature remains neutral with regard to jurisdictional claims in published maps and institutional affiliations.

(c) The Author(s), under exclusive licence to Springer Nature Limited 2020 
a
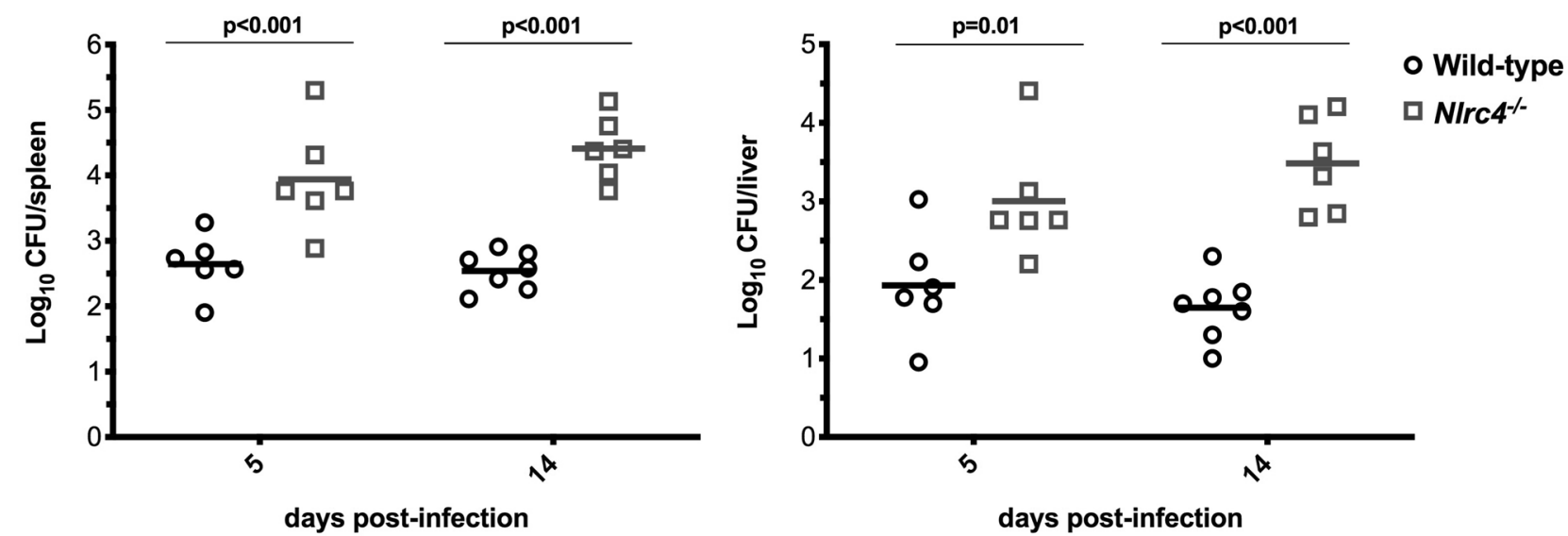

b
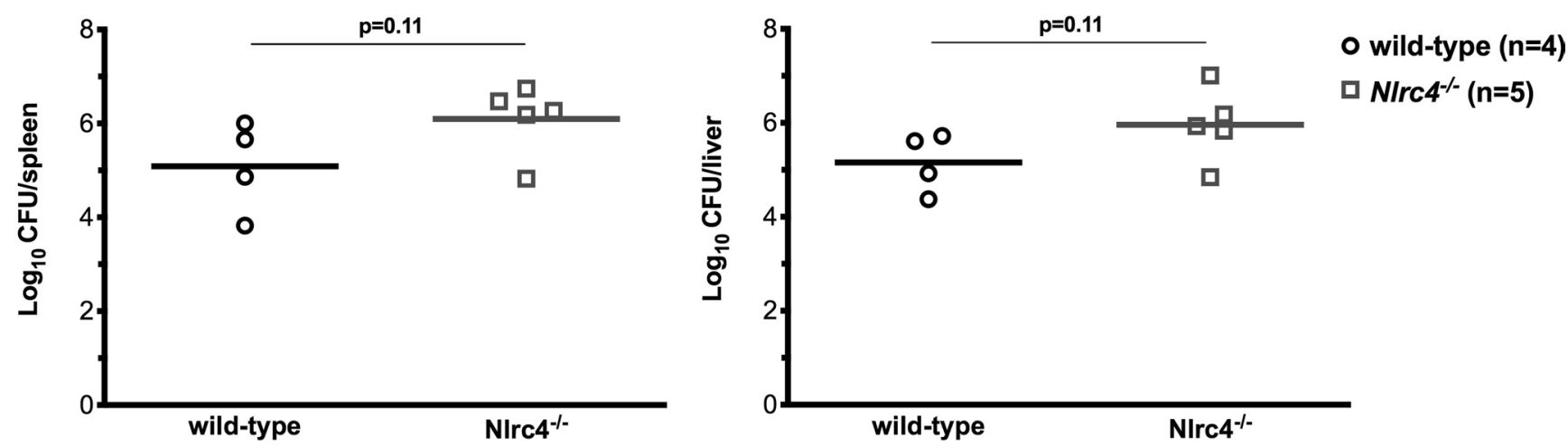

Extended Data Fig. 1 | NLRC4 is required to restrict microbial spread during an oral sub-lethal but not an oral lethal infection with S. Typhimurium. a, Wild-type and n/rc4 $4^{-/-}$mice were challenged orally with $4.4 \times 10^{9} \mathrm{CFU}$ S. Typhimurium M525P to establish a sub-lethal infection and microbial burden was determined in the spleen and liver at 5 days ( $n=6$ for wild-type and N/rc $\left.4^{-/-}\right)$and 14 days $\left(n=7\right.$ for wild-type and $n=6$ for N/rc $\left.4^{-/-}\right)$post-challenge. b, Wild type and NIrc4 ${ }^{-/-}$mice were challenged orally $8 \times 10^{8} \mathrm{CFU}$ S. Typhimurium SL1344 to establish a lethal infection and microbial burden was determined in the spleen and liver at 4 days post-challenge. Each symbol represents one mouse and horizontal lines delineate the mean. Statistical significance was calculated by 2-way ANOVA followed by Sidak's multiple comparisons test for a and two-tailed Mann Whitney test for $\mathbf{b}$. Data are representative of two independent experiments. 


\section{$\square 10^{3} \mathrm{CFU}(\mathrm{n}=5) \quad \square 10^{4} \mathrm{CFU}(\mathrm{n}=6) \quad 10^{5} \mathrm{CFU}(\mathrm{n}=6)$}

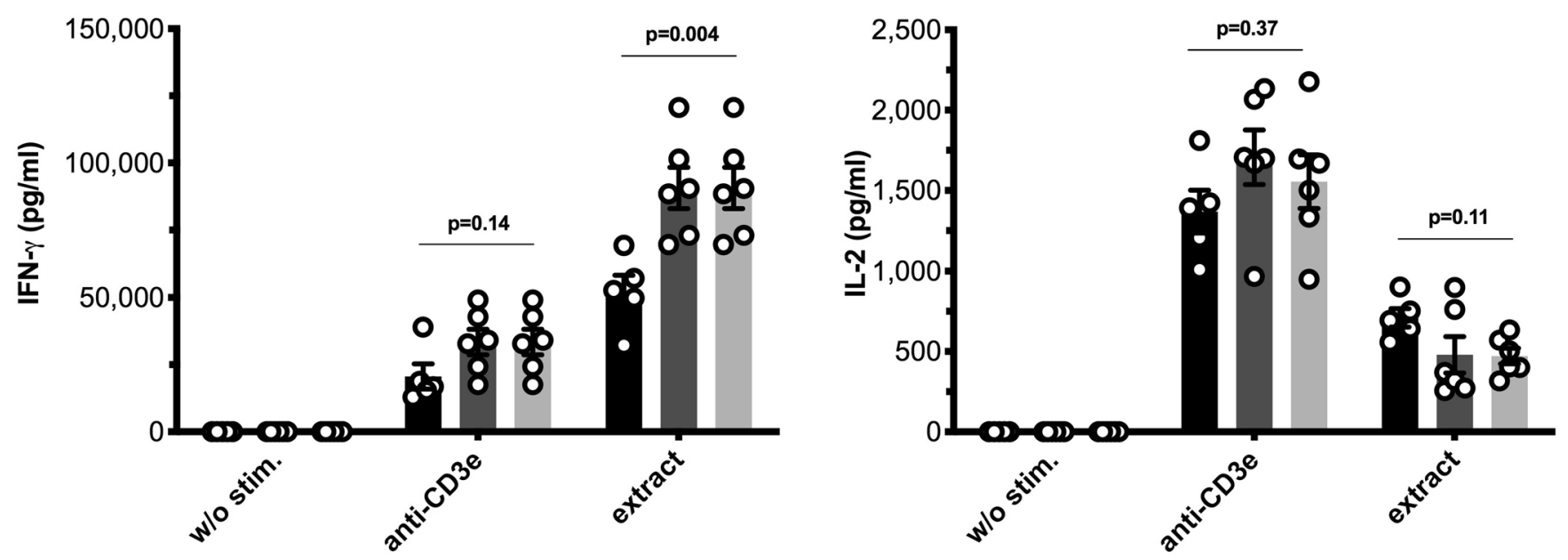

Extended Data Fig. 2 | The effect of infection dose on the potency of ex vivo CD4+ T cell-mediated responses. Wild-type mice were challenged with either $1.58 \times 10^{5} \mathrm{CFU}, 1.72 \times 10^{4} \mathrm{CFU}$ or $1.53 \times 10^{3} \mathrm{CFU}$ S. Typhimurium M525P. Mice were euthanised 104-125 days after challenge and their splenic CD4+ T cells were stimulated with medium only (w/o stim.), anti-mouse CD3e (anti-CD3e) or whole bacterial cell extract (extract). $\mathbf{a}$, IFN- $\gamma$ measured by ELISA in the cell culture supernatant after 72 hours. b, IL-2 measured by ELISA in the cell culture supernatant after 24 hours. Data are shown as mean \pm s.e.m. Statistical significance was calculated by a one-way ANOVA. Data were generated from one experiment. 


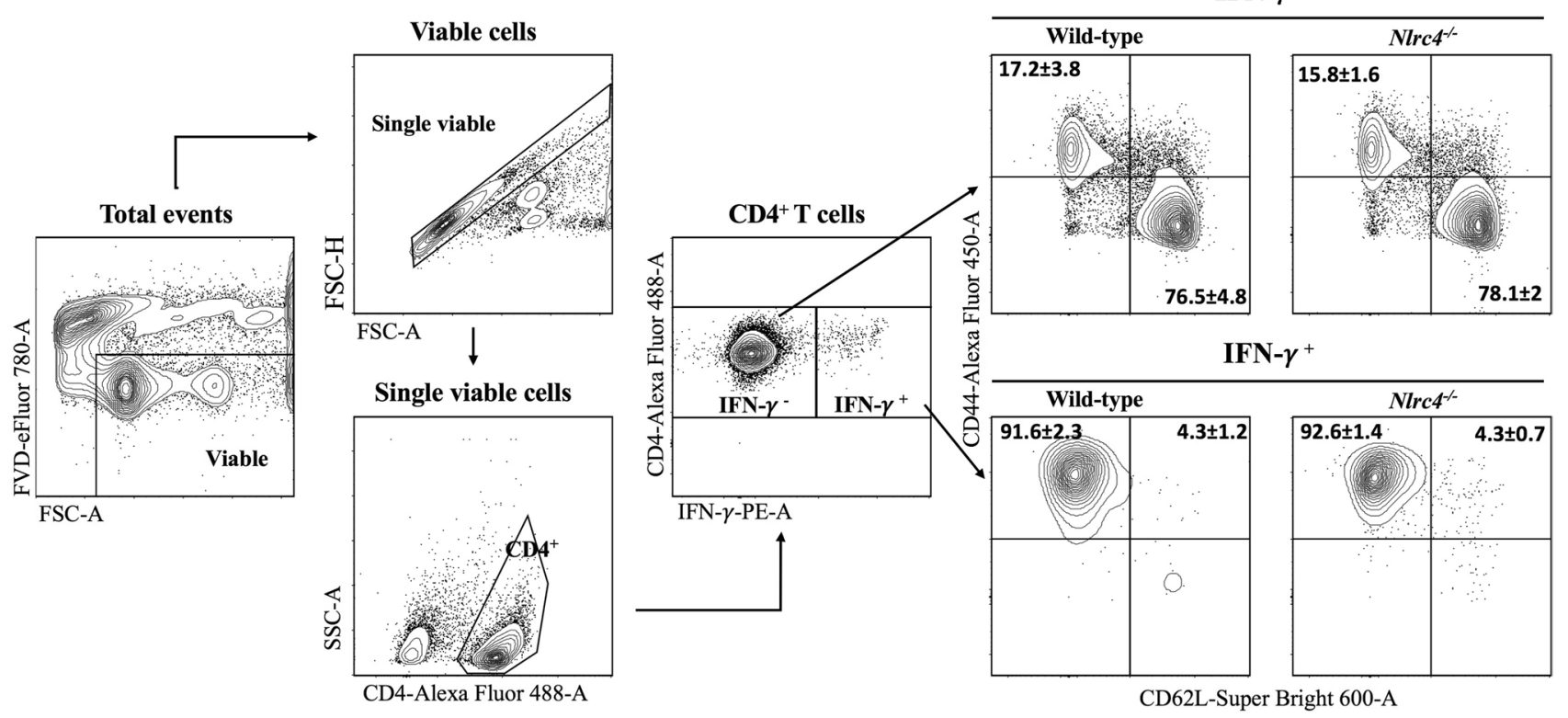

Extended Data Fig. 3 | Flow cytometric analysis reveals that CD4 ${ }^{+} \mathrm{T}$ cells secreting IFN- $\gamma$ ex vivo have the profile of effector memory, rather than central memory, $\mathrm{CD}^{+} \mathrm{T}$ cells. CD4 ${ }^{+} \mathrm{T}$ cells isolated from the spleen of wild-type and N/rc4-/- mice 100 days after primary challenge with $1.24 \times 10^{4} \mathrm{CFU}$ S. Typhimurium M525P were stimulated ex vivo with whole bacterial cell extract and phenotypically characterised via flow cytometry. Viable cells were first selected using a fixable viability dye (FVD) and single cells only were further included in the analysis based on their forward scatter area vs. forward scatter height. Single viable cells expressing CD4 were then separated to IFN- $\gamma$ - and IFN- $\gamma^{+}$with both groups analysed for expression of CD44 and CD62L. For CD4+IFN- $\gamma$ cells, the phenotype CD44+CD62-represents effector T cells, while the phenotype CD44-CD62+ represents naïve T cells. For CD4+IFN- $\gamma^{+}$ cells, the phenotype CD44+CD62-represents effector memory T cells, while the phenotype $\mathrm{CD} 44^{+} \mathrm{CD} 62^{+}$represents central memory $T$ cells. Percentages shown in the respective quadrants are mean values $\pm \mathrm{SD}$ from $\mathrm{N}=5$ wild-type and $\mathrm{N}=6 \mathrm{~N} / \mathrm{rc} 4^{-/-}$mice. Data were generated from one experiment. 
a

Median survival (days)

$\begin{array}{ll}\Theta \text { Wild-type }(n=24) & 8 \\ \forall \operatorname{Nirc4}^{--}(n=24) & 9\end{array}$

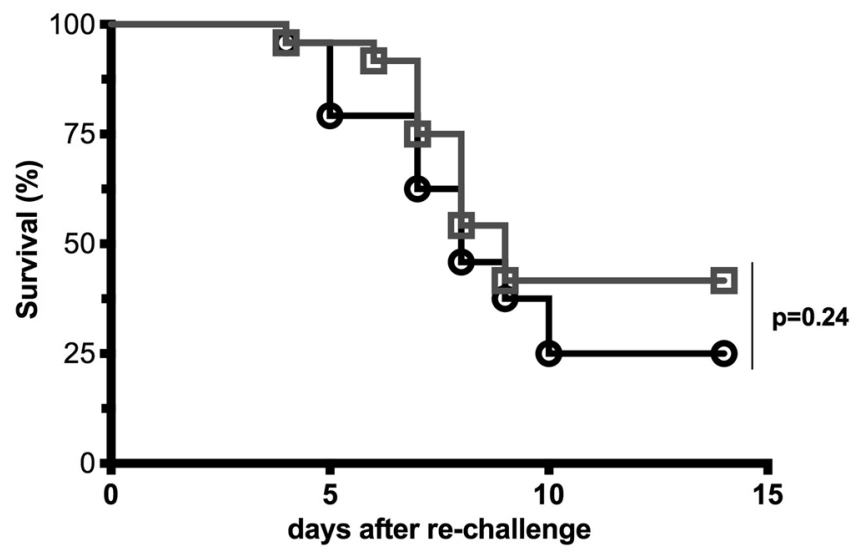

b

Median survival (days)

$\begin{array}{ll}\Theta \text { Wild-type }(n=12) & 8 \\ \exists \text { NIrc4 }^{-/-}(n=9) & 6\end{array}$

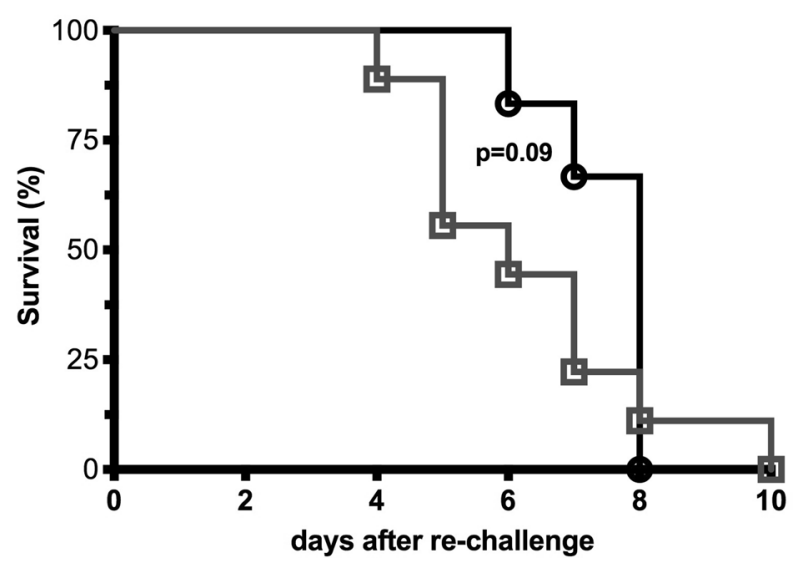

Extended Data Fig. 4 | NLRC4 does not affect protection against lethal re-challenge. Wild-type and N/rc4 $4^{-/-}$mice were challenged with either sterile PBS (naïve) or 1-1.15 $\times 10^{4}$ CFU S. Typhimurium M525P and allowed to clear the primary infection for 90-106 days. They were then re-challenged orally with 1.37-7.2 $\times 10^{7}$ CFU S. Typhimurium SL1344 to establish a lethal infection and inspected twice daily. They were euthanized upon detection of adverse signs and a humane end point curve was constructed for $\mathbf{a}$, naïve mice and $\mathbf{b}$, mice 'immunised' with Salmonella. Data has been pooled from 2 independent experiments. Statistical significance was calculated by a two-sided log-rank test. 


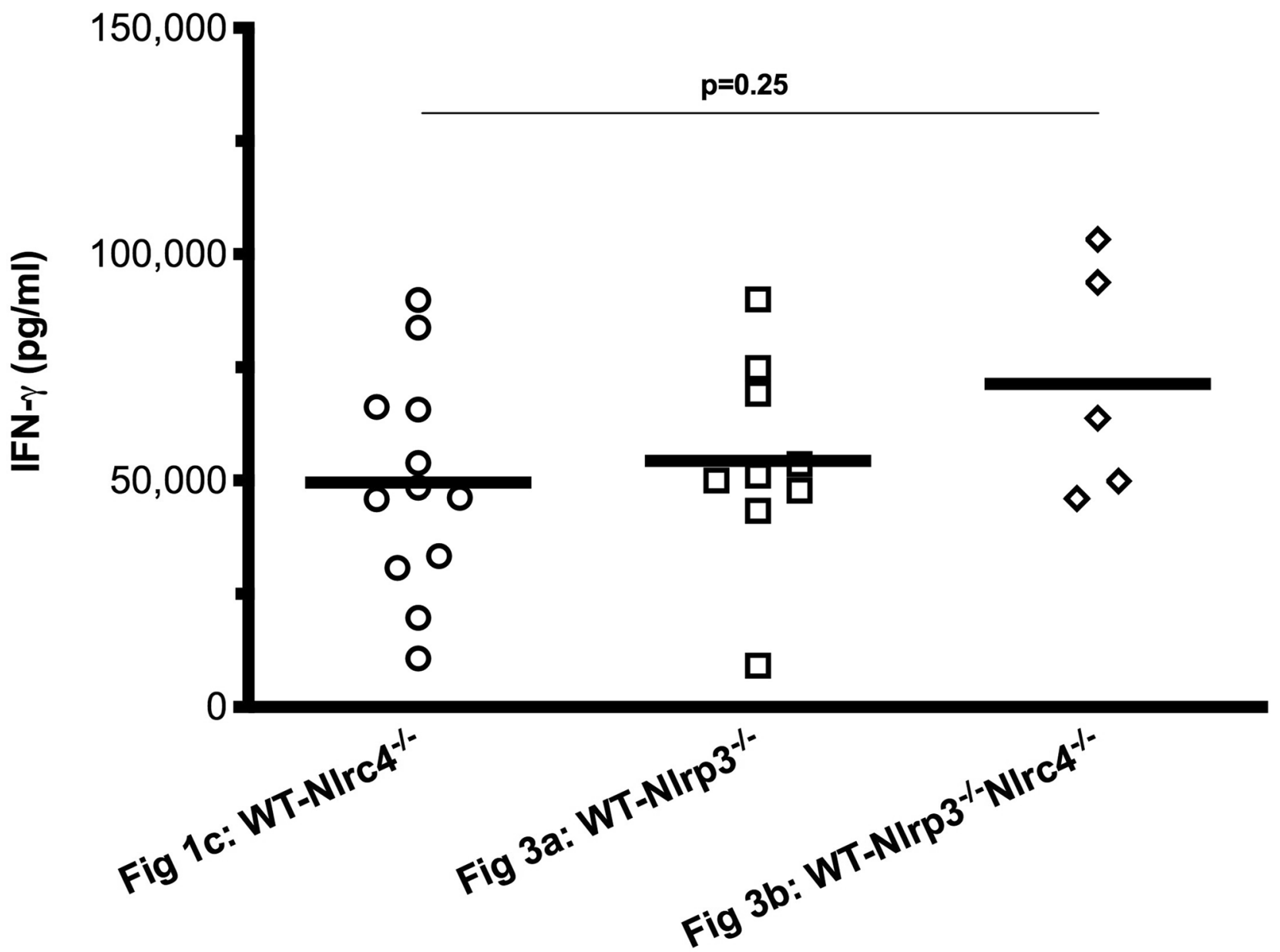

Extended Data Fig. 5 | Data variation between independent trials comparing CD4+ T cell-mediated responses in wild-type, NIrc4\%, NIrp3\% and Nlrp3 ${ }^{\prime-N} \mathrm{NIrC4}{ }^{-/}$mice is not statistically significant. Levels of IFN- $\gamma$ produced by $\mathrm{CD} 4^{+} \mathrm{T}$ cells stimulated ex vivo with whole bacterial cell extract were compared between wild-type mice used in three independent trials shown in Fig. 1c, Fig. 3a and Fig. 3b. Each symbol represents one mouse and horizontal lines delineate the mean. The data was tested for statistical significance by one-way ANOVA. 
a

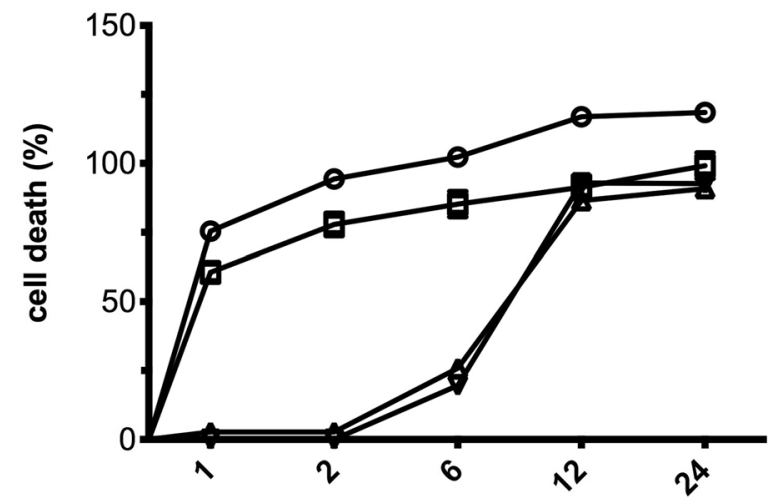

hours post-infection b

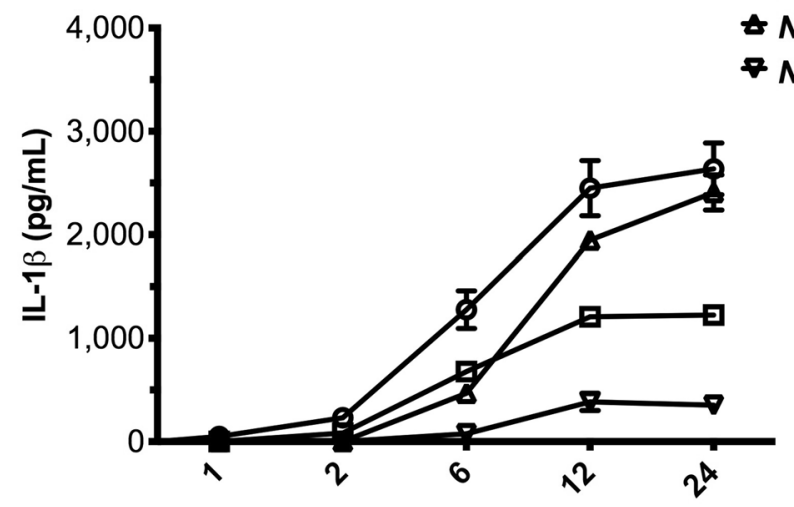

hours post-infection

Extended Data Fig. 6 | In the absence of NLRC4, Salmonella-infected macrophages do not undergo early cell death enabling them to survive longer and

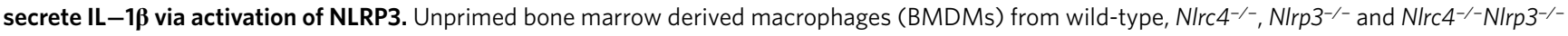
mice were infected with S. Typhimurium M525P in logarithmic growth at the MOI=50. a, Cytotoxicity was determined by measuring levels of LDH released in the cell culture supernatant. $\mathbf{b}$, Levels of IL- $1 \beta$ were determined by ELISA in the cell culture supernatant. Data are shown as mean of triplicate wells \pm s.e.m. Data are representative of two independent experiments. 
M525P

MG1 655

M525P

MG1655

M525P

MG1655

M525P

MG1655

M525P

MG1655

M525P

MG1655

M525P

MG1655

M525P

MG1655

M525P

MG1655
MAQVINTNSLSLLTQNNLNKSQSALGTAIERLSSGLRINSAKDDAAGQAIANRFTANIKG MAQVINTNSLSLITQNNINKNQSALSSSIERLSSGLRINSAKDDAAGQAIANRFTSNIKG

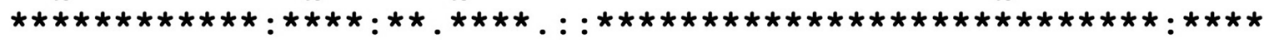

LTQASRNANDGISIAQTTEGALNEINNNLQRVRELAVQSANSTNSQSDLDSIQAEITQRL LTQAARNANDGISVAQTTEGALSEINNNLQRVRELTVQATTGTNSESDLSSIQDEIKSRL

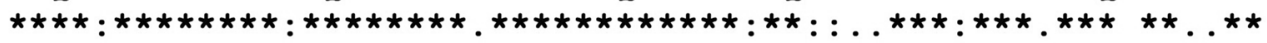

NEIDRVSGQTQFNGVKVLAQDNTLTIQVGANDGETIDIDLKQINSQTLGLDTLNVQQKYK DEIDRVSGQTQFNGVNVLAKNGSMKIQVGANDNQTITIDLKQIDAKTLGLDGFSVKNNDT

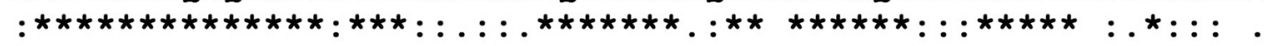

VSDTAATVTGYADTT---IALDNSTFKA-SATGLGGTDQKIDGDLKFDDTTGKYYAKVTV VTTSA-PVTAFGATTTNNIKLTGITLSTEAATDTGGTNPA-SIEGVYTDNGNDYYAKI--

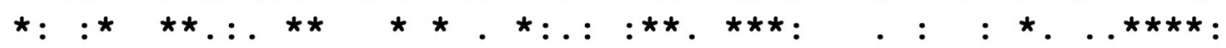

TGGTGKDGYYEVSVDKTNGEVTLAGGATSPLTGGLPATATEDVKNVQVANADLTEAKAAL TGGDNDGKYYAVTVAN-DGTVTMATGATANATVTDANT--TKATTITSGGTPVQIDNTAG

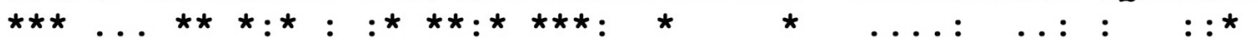

TAAGVTGTASVVKMSYTDNNGKTIDG-GLAVKVGDDYYSATQNKDGSISINTTKYTADDG SATANLGAVSLVKLQ--DSKGNDTDTYALKDTNGNLYAADVNETTGAVSVKTITYTDSSG

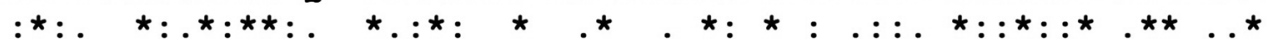

T-SKTALNKLGGADGKTEVVSIGGKTYAASKAEGHNFKAQPD-----LAEAAATTTENPL AASSPTAVKLGGDDGKTEVVDIDGKTYDSADLNGGNLQTGLTAGGEALTAVANGKTTDPL

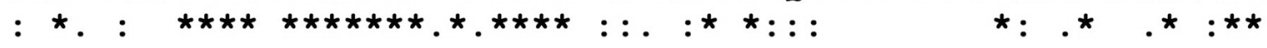
QKIDAALAQVDTLRSDLGAVQNRFNSAITNLGNTVNNLTSARSRIEDSDYATEVSNMSRA KALDDAIASVDKFRSSLGAVQNRLDSAVTNLNNTTTNLSEAQSRIQDADYATEVSNMSKA $:: \star \star: \star . \star \star .: \star \star . \star \star \star \star \star \star \star:: * \star: \star \star \star . \star \star . . \star \star: . \star: \star \star \star: \star: \star \star \star \star \star \star \star \star \star \star: *$

QILQQAGTSVLAQANQVPQNVLSLLR- 495 QIIQQAGNSVLAKANQVPQQVLSLLQG 498

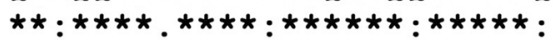

60

60

120

120

180

180

236

236

296

293

355

351

409

411

469

471

Extended Data Fig. 7 | Pairwise Sequence Alignment of FliC from E. coli K-12 MG1655 and S. Typhimurium M525P. Comparison of the predicted FliC proteins from S. Typhimurium M525P and E. coli K-12 MG1655 by Clustal Omega (EMBL-EBI). 
a

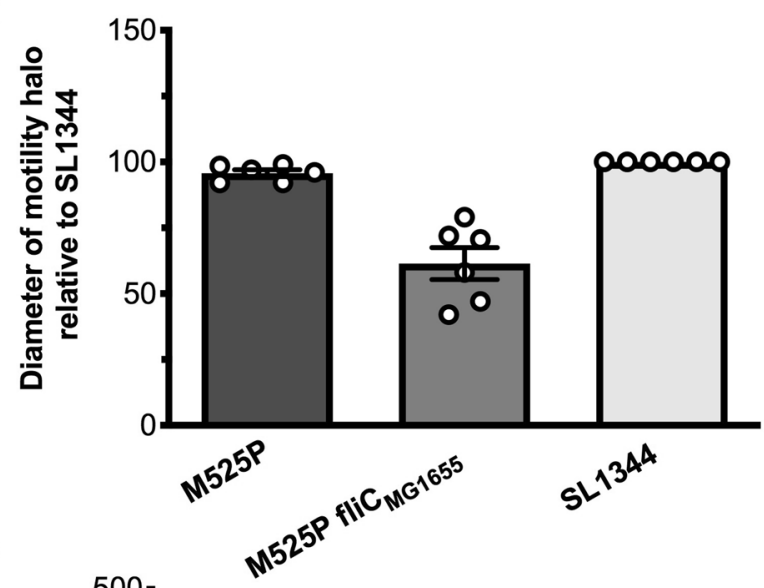

b

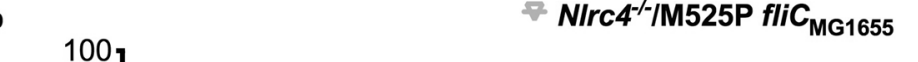

$\Theta$ Wild-type/525P

$\exists$ Wild-type/M525P fliC $_{\text {MG1655 }}$

$\triangle$ Nirc $^{-1 / 1525 P}$

- NIrc4-/M525P fliC MG1655 c

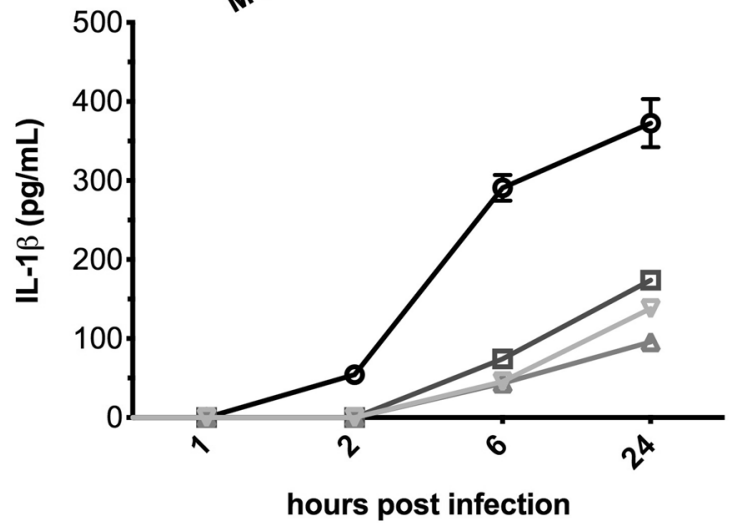

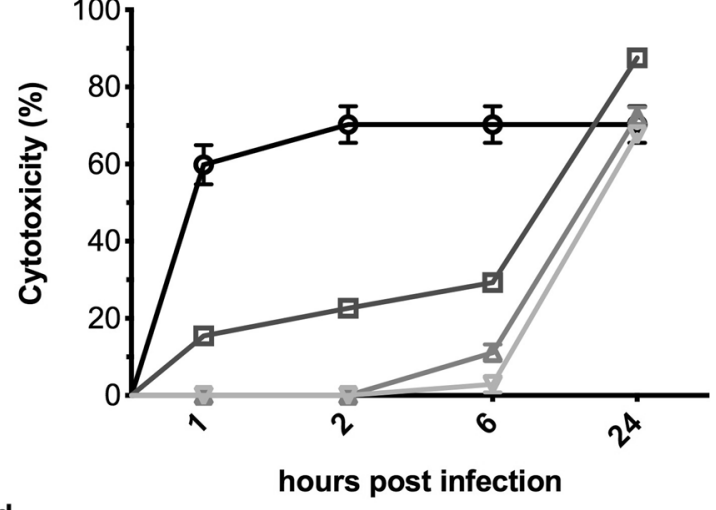

d

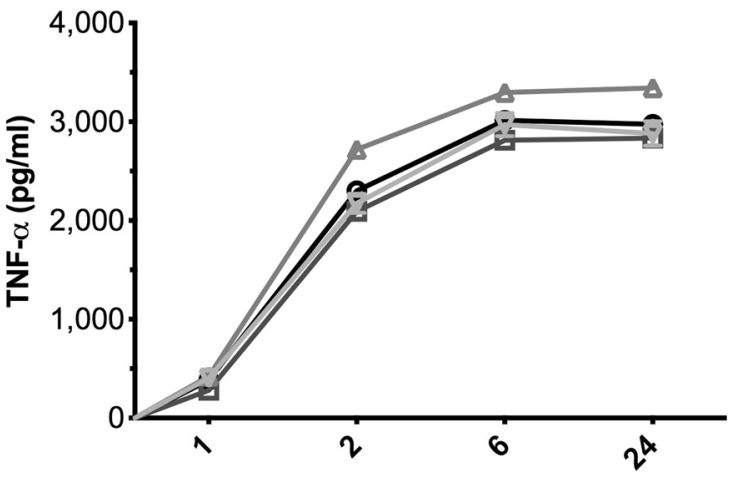

hours post-infection

Extended Data Fig. 8 | Salmonella expressing flagellin from non-pathogenic E. coli (M525P fliC $\left.{ }_{M G 1655}\right)$ is motile but impaired at activating the NLRC4

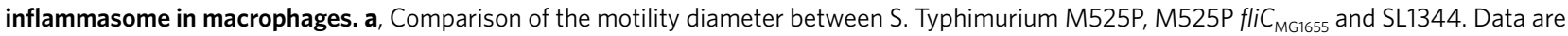
expressed as \% of the diameter achieved by the SL1344. b-d, Unprimed bone marrow derived macrophages from wild-type and N/rc4 ${ }^{-/-}$mice were infected for $1 \mathrm{~h}, 2 \mathrm{~h}, 6 \mathrm{~h}$ and $24 \mathrm{~h}$ with S. Typhimurium M525P or M525P fli $\mathrm{MG}_{\mathrm{MG} 55}$ in logarithmic growth. $\mathbf{b}$, Cytotoxicity was determined by measuring levels of $L D H$ released in the cell culture supernatant at an $\mathrm{MOI}$ of 50 . c, Levels of IL-1 $\beta$ and d, TNF- $\alpha$ were determined by ELISA in the cell culture supernatant at an $\mathrm{MOI}$ of 1. Data has been pooled from 6 independent experiments and shown as mean \pm s.e.m. in $\mathbf{a}$. Data are representative of two independent experiments in b-d and shown as mean of triplicate wells \pm s.e.m. 


\section{Reporting Summary}

Nature Research wishes to improve the reproducibility of the work that we publish. This form provides structure for consistency and transparency in reporting. For further information on Nature Research policies, see Authors \& Referees and the Editorial Policy Checklist.

\section{Statistics}

For all statistical analyses, confirm that the following items are present in the figure legend, table legend, main text, or Methods section.

n/a $\mid$ Confirmed

$\square$ The exact sample size $(n)$ for each experimental group/condition, given as a discrete number and unit of measurement

$\square$ \ A statement on whether measurements were taken from distinct samples or whether the same sample was measured repeatedly

The statistical test(s) used AND whether they are one- or two-sided

$\square$ Only common tests should be described solely by name; describe more complex techniques in the Methods section.

$\bigotimes \square$ A description of all covariates tested

$\square$ \ A description of any assumptions or corrections, such as tests of normality and adjustment for multiple comparisons

$\square$ A full description of the statistical parameters including central tendency (e.g. means) or other basic estimates (e.g. regression coefficient)

$\square$ AND variation (e.g. standard deviation) or associated estimates of uncertainty (e.g. confidence intervals)

$\square$ For null hypothesis testing, the test statistic (e.g. $F, t, r$ ) with confidence intervals, effect sizes, degrees of freedom and $P$ value noted

$\square$ Give P values as exact values whenever suitable.

Х $\square$ For Bayesian analysis, information on the choice of priors and Markov chain Monte Carlo settings

Х $\square$ For hierarchical and complex designs, identification of the appropriate level for tests and full reporting of outcomes

Х $\square$ Estimates of effect sizes (e.g. Cohen's $d$, Pearson's $r$ ), indicating how they were calculated

Our web collection on statistics for biologists contains articles on many of the points above.

\section{Software and code}

Policy information about availability of computer code

Data collection FlowJo 7.6.5 and Attune NxT 3.1 for collection of Flow Cytometry data

Data analysis Graph Pad Prism 8.0, FlowJo 10.6.0

For manuscripts utilizing custom algorithms or software that are central to the research but not yet described in published literature, software must be made available to editors/reviewers. We strongly encourage code deposition in a community repository (e.g. GitHub). See the Nature Research guidelines for submitting code \& software for further information.

\section{Data}

Policy information about availability of data

All manuscripts must include a data availability statement. This statement should provide the following information, where applicable:

- Accession codes, unique identifiers, or web links for publicly available datasets

- A list of figures that have associated raw data

- A description of any restrictions on data availability

The data supporting the findings shown in Fig 1-6 and Extended Data Fig 1-2, 4-6 and 8 are available as Statistical Source Data with this manuscript. Data are also publicly available in Cambridge Research Repository Apollo with the identifier https://doi.org/10.17863/CAM.41575

\section{Field-specific reporting}

Please select the one below that is the best fit for your research. If you are not sure, read the appropriate sections before making your selection. 


\section{Life sciences study design}

All studies must disclose on these points even when the disclosure is negative.

Sample size Sample sizes were based on previous experience and were large enough to detect differences between samples with biological significance.

Data exclusions

Replication

Randomization

Blinding

\section{no data were excluded}

Experimental findings were verified by independent biological repeats as described in the figure legends.

\section{Reporting for specific materials, systems and methods}

We require information from authors about some types of materials, experimental systems and methods used in many studies. Here, indicate whether each material, system or method listed is relevant to your study. If you are not sure if a list item applies to your research, read the appropriate section before selecting a response.

Materials \& experimental systems

\begin{tabular}{l|l}
\hline$n / a$ & Involved in the study \\
$\square$ & $\bigotimes$ Antibodies \\
$\square$ & $\square$ Eukaryotic cell lines \\
$\square$ Palaeontology \\
$\square$ Animals and other organisms \\
$\square$ Human research participants \\
$\square$ Clinical data
\end{tabular}

\begin{tabular}{l|l} 
Methods \\
\hline n/a & Involved in the study \\
$\square$ & $\square$ ChIP-seq \\
$\square$ & $\bigotimes$ Flow cytometry \\
$\square$ & $\square$ MRI-based neuroimaging
\end{tabular}

\section{Antibodies}

Antibodies used

all antibodies have been described in Methods

Validation

All of the antibodies used have been validated by the manufacturers and have been extensively used in the field.

\section{Eukaryotic cell lines}

Policy information about cell lines

Cell line source(s)

State the source of each cell line used.

Authentication

Describe the authentication procedures for each cell line used OR declare that none of the cell lines used were authenticated.

Mycoplasma contamination

Confirm that all cell lines tested negative for mycoplasma contamination OR describe the results of the testing for

mycoplasma contamination OR declare that the cell lines were not tested for mycoplasma contamination.

Commonly misidentified lines Name any commonly misidentified cell lines used in the study and provide a rationale for their use. (See ICLAC register)

\section{Palaeontology}

Specimen provenance

Provide provenance information for specimens and describe permits that were obtained for the work (including the name of the issuing authority, the date of issue, and any identifying information).

Specimen deposition

Indicate where the specimens have been deposited to permit free access by other researchers.

Dating methods

If new dates are provided, describe how they were obtained (e.g. collection, storage, sample pretreatment and measurement), where they were obtained (i.e. lab name), the calibration program and the protocol for quality assurance OR state that no new dates are provided.

Tick this box to confirm that the raw and calibrated dates are available in the paper or in Supplementary Information. 


\section{Animals and other organisms}

Policy information about studies involving animals; ARRIVE guidelines recommended for reporting animal research

Laboratory animals

mouse, C57BL/6J genetic background, wild-type and genetically altered, male and female, used at 8-24 weeks of age

Wild animals

the study did not involve wild animals

Field-collected samples

the study did not involve samples collected in the field

Ethics oversight

All experiments were performed after approval from the University of Cambridge ethical review committee and under the UK government Home office regulations license numbers 80/2135, 80/11763, PF86EABB1 and P48B8DA35.

Note that full information on the approval of the study protocol must also be provided in the manuscript.

\section{Human research participants}

Policy information about studies involving human research participants

Population characteristics Describe the covariate-relevant population characteristics of the human research participants (e.g. age, gender, genotypic information, past and current diagnosis and treatment categories). If you filled out the behavioural \& social sciences study design questions and have nothing to add here, write "See above."

Recruitment Describe how participants were recruited. Outline any potential self-selection bias or other biases that may be present and how these are likely to impact results.

Ethics oversight

Identify the organization(s) that approved the study protocol.

Note that full information on the approval of the study protocol must also be provided in the manuscript.

\section{Clinical data}

Policy information about clinical studies

All manuscripts should comply with the ICMJE guidelines for publication of clinical research and a completed CONSORT checklist must be included with all submissions.

Clinical trial registration

Provide the trial registration number from ClinicalTrials.gov or an equivalent agency.

Study protocol

Note where the full trial protocol can be accessed OR if not available, explain why.

Data collection

Describe the settings and locales of data collection, noting the time periods of recruitment and data collection.

Outcomes

Describe how you pre-defined primary and secondary outcome measures and how you assessed these measures.

\section{ChIP-seq}

\section{Data deposition}

$\square$ Confirm that both raw and final processed data have been deposited in a public database such as GEO.

$\square$ Confirm that you have deposited or provided access to graph files (e.g. BED files) for the called peaks.

Data access links

May remain private before publication.

Files in database submission

Genome browser session (e.g. UCSC)

\section{Methodology}

Replicates

Sequencing depth

Antibodies
For "Initial submission" or "Revised version" documents, provide reviewer access links. For your "Final submission" document, provide a link to the deposited data.

Provide a list of all files available in the database submission.

Provide a link to an anonymized genome browser session for "Initial submission" and "Revised version" documents only, to enable peer review. Write "no longer applicable" for "Final submission" documents.

Describe the experimental replicates, specifying number, type and replicate agreement.

Describe the sequencing depth for each experiment, providing the total number of reads, uniquely mapped reads, length of reads and whether they were paired-or single-end.

Describe the antibodies used for the ChIP-seq experiments; as applicable, provide supplier name, catalog number, clone name, and lot number. 
Peak calling parameters

Specify the command line program and parameters used for read mapping and peak calling, including the ChIP, control and index files used.

Data quality

Describe the methods used to ensure data quality in full detail, including how many peaks are at FDR 5\% and above 5-fold enrichment.

Software

Describe the software used to collect and analyze the ChIP-seq data. For custom code that has been deposited into a community repository, provide accession details.

\section{Flow Cytometry}

Plots

Confirm that:

$\bigotimes$ The axis labels state the marker and fluorochrome used (e.g. CD4-FITC).

$\bigotimes$ The axis scales are clearly visible. Include numbers along axes only for bottom left plot of group (a 'group' is an analysis of identical markers).

\All plots are contour plots with outliers or pseudocolor plots.

$\bigotimes$ A numerical value for number of cells or percentage (with statistics) is provided.

\section{Methodology}

Sample preparation

Single cell suspensions were prepared from mouse spleen as described in Methods. Non-specific binding was prevented by incubating cells with anti-mouse CD16/CD32. Directly conjugated antibodies were used at the concentration recommended by the manufacturer and cells were stained in V-bottom 96-well plates

Instrument DxP Multi-color updated FACSCan (BD), Attune NxT Flow Cytometer (Invitrogen)

Software

DxP Multi-color updated FACSCan (BD): FlowJo to collect and analyse. Attune NxT Flow Cytometer: Attune NxT software to collect, FlowJo to analyse.

Cell population abundance

no cell sorting was performed

Gating strategy

the gating strategy is shown in Supplementary Fig 2 and Extended Data Fig 3

\ Tick this box to confirm that a figure exemplifying the gating strategy is provided in the Supplementary Information.

\section{Magnetic resonance imaging}

\section{Experimental design}

Design type

Design specifications

Behavioral performance measures

\section{Acquisition}

Imaging type(s)

Field strength

Sequence \& imaging parameters

Area of acquisition

Diffusion MRI

$\square$ Used

Preprocessing

Preprocessing software

\section{Indicate task or resting state; event-related or block design}

Specify the number of blocks, trials or experimental units per session and/or subject, and specify the length of each tria or block (if trials are blocked) and interval between trials.

State number and/or type of variables recorded (e.g. correct button press, response time) and what statistics were used to establish that the subjects were performing the task as expected (e.g. mean, range, and/or standard deviation across subjects).
Specify: functional, structural, diffusion, perfusion.

\section{Specify in Tesla}

Specify the pulse sequence type (gradient echo, spin echo, etc.), imaging type (EPI, spiral, etc.), field of view, matrix size, slice thickness, orientation and TE/TR/flip angle.

State whether a whole brain scan was used OR define the area of acquisition, describing how the region was determined.

Not used
Provide detail on software version and revision number and on specific parameters (model/functions, brain extraction, segmentation, smoothing kernel size, etc.). 
Normalization

Normalization template

Noise and artifact removal

Volume censoring
If data were normalized/standardized, describe the approach(es): specify linear or non-linear and define image types used for transformation OR indicate that data were not normalized and explain rationale for lack of normalization.

Describe the template used for normalization/transformation, specifying subject space or group standardized space (e.g. original Talairach, MNI305, ICBM152) OR indicate that the data were not normalized.

Describe your procedure(s) for artifact and structured noise removal, specifying motion parameters, tissue signals and physiological signals (heart rate, respiration).

Define your software and/or method and criteria for volume censoring, and state the extent of such censoring.

\section{Statistical modeling \& inference}

Model type and settings

Effect(s) tested

Specify type of analysis:

Statistic type for inference

(See Eklund et al. 2016)

\section{Correction}

Models \& analysis

\begin{tabular}{l|l|l|l|l|l}
$\square$ & Functional and/or effective connectivity
\end{tabular} (Carlo).
Specify type (mass univariate, multivariate, RSA, predictive, etc.) and describe essential details of the model at the first and second levels (e.g. fixed, random or mixed effects; drift or auto-correlation).

Define precise effect in terms of the task or stimulus conditions instead of psychological concepts and indicate whether ANOVA or factorial designs were used.

Whole brain $\square$ ROI-based $\square$ Both

Specify voxel-wise or cluster-wise and report all relevant parameters for cluster-wise methods.

Describe the type of correction and how it is obtained for multiple comparisons (e.g. FWE, FDR, permutation or Monte 